\title{
Axial Impact Resistance of FRP-Confined Concrete
}

Thong M. Pham ${ }^{1}$ and Hong $\mathrm{Hao}^{2}$

\section{Abstract}

This study investigates the impact resistance of fiber reinforced polymer (FRP) confined concrete. Concrete cylinders were wrapped with carbon FRP (CFRP) or glass FRP (GFRP) with a varied number of layers and wrapping schemes. The impact tests were conducted by using drop-weight apparatus at different impact velocities. Dynamic behavior of the specimens has been investigated. The experimental results have shown that the failure modes are very different from those from static tests. Identical specimens experienced different damages as the impact velocities changed. The dynamic rupture strain of FRP was found to be substantially lower as compared to that under static loads. As a result, the FRP efficiency factors were found to be 0.17 and 0.56 for CFRP and GFRP, respectively. Interestingly, although GFRP has lower tensile strength and elastic modulus, it showed much better performance against impact as compared to CFRP in terms of both the strength and ductility. The higher rupture strain of GFRP compared to CFRP is one of the reasons resulting in higher confinement efficiency of GFRP under impact loads. A confinement model is proposed to predict the confined concrete strength under impact.

Keywords: Fiber Reinforced Polymer; Impact loading; Impact resistance; Strengthening;

\footnotetext{
${ }^{1}$ Research Fellow, Center for Infrastructural Monitoring and Protection, School of Civil and Mechanical Engineering, Curtin University, Kent Street, Bentley, WA 6102, Australia. Email: thong.pham@curtin.edu.au

${ }^{2}$ John Curtin Distinguished Professor, Center for Infrastructural Monitoring and Protection, School of Civil and Mechanical Engineering, Curtin University, Kent Street, Bentley, WA 6102, Australia (corresponding author). Email: hong.hao@curtin.edu.au
} 
21 Concrete columns wrapped with fiber reinforced polymer (FRP) have shown excellent performances on load carrying capacity and ductility. FRP provides the confinement to the concrete columns and thus improves their performance. There are many experimental and analytical studies investigating the behavior of FRP-confined concrete under static loads (Cusson and Paultre 1995; Spoelstra and Monti 1999; Lam and Teng 2002; Wu and Zhou 2010; Pham et al. 2015a). The behavior of FRP-confined concrete under static loads is quite well understood as compared to that under other extreme loading conditions like earthquake, blast loads, and impact loads (Pham and Hao 2016a). The effectiveness of FRP has been proven and thus the FRP-confined concrete may be used in high-rise buildings, large-span bridges, subway stations, and military facilities. Among these applications of FRP, concrete columns wrapped with FRP may suffer from impulsive loads with high loading rates. For example, bridge piers or under-ground structures may be subjected to impacts from moving vehicles, residential or military facilities may subject to impact accidents or bomb attacks. Unfortunately, research on impact resistance and structural behavior against impulsive loads is still limited (Pham and Hao 2016b). Especially, studies about impact resistance of FRP-confined concrete are rare. There have been only some limited relevant studies about confined concrete columns under impact loads in the literature (Shan et al. 2007; Uddin et al. 2008; Mutalib and Hao 2011a; Mutalib and Hao 2011b; Xiao and Shen 2012; Xu et al. 2012).

Shan et al. (2007) used gas gun equipment to investigate the impact resistance of confined concrete filled steel tubes, in which concrete was filled in a steel tube that was externally wrapped with FRP sheets. The maximum strain rate from these tests ranged between 389 and $1621 \mathrm{~s}^{-1}$ (strain per second). Damage to these specimens under impact loads was localized to the vicinity of the impact end, in which the CFRP sheets near the impact end fractured. The 
authors concluded that using FRP confinement can significantly improve the compressive strength of the specimens under impact loads.

Uddin et al. (2008) used an Instron drop-tower testing machine to carry out impact tests on concrete specimens wrapped with thermoplastic composite jackets or CFRP sheets. A comparison between specimens with the two different wrapping materials had been conducted. It was found that rupturing of the CFRP sheets under impact loads led to a brittle failure of the CFRP-confined concrete specimens. The failure of FRP-confined concrete was reported at the mid height of the specimens, which was different from the observation by Shan et al. (2007). The impact velocity can be a reason for this difference in which the impact velocity was 2.4 $\mathrm{m} / \mathrm{s}$, much slower than those in the tests by Shan et al. (2007). It seems that the impact velocity has changed the failure pattern.

Meanwhile, Xiao and Shen (2012) conducted a study on impact behaviors of CFRP-confined concrete filled tubes (CCFT) under a drop-weight test system. CFRP sheets ruptured at 2 milliseconds after the impact event. The progressive failure of the CCFT specimens initiated at the specimen top and then propagated down to the mid height. This failure pattern was similar to that of the study by Shan et al. (2007). The maximum drop height of this study was $7 \mathrm{~m}$, which is equivalent to a velocity of $11.7 \mathrm{~m} / \mathrm{s}$. The CCFT specimens had shown improved impact damage resistance. By increasing the number of CFRP layers, damage of the specimens reduced under the constant impact energy. This finding proved that CFRP confinement can be used to improve the impact resistance of specimens. The experimental results have shown that an increase in the impact energy did not significantly change the maximum impact load but the impact duration.

The above studies have presented some qualitative observations from testing. However, only very limited quantitative analysis was reported in literature, especially the tests and analyses 
related to FRP wrapped concrete are very limited. In particular, it is necessary to investigate the failure mode of FRP-confined concrete and quantify the confinement effect on the confined concrete. This study aims to examine the impact resistance of FRP-confined concrete. Rupture strain of FRP, which governs the failure of FRP-confined concrete, is investigated against different impact velocities. Actual FRP rupture strain is considered for predicting the axial impact resistance of FRP-confined concrete. The confinement efficiency of CFRP against GFRP, which is more ductile, under impact loads is examined. The confinement mechanism of FRP-confined concrete with double confinement effects from FRP and lateral inertia forces is also studied.

\section{Confinement mechanism}

\section{Confinement effect in static loads}

When a FRP-confined concrete column is subjected to axial compression, it expands laterally. This expansion is prevented by the FRP jacket, which provides confining pressure to the concrete core. Since the lateral confining pressure is activated, the axial stress of FRP-confined concrete is thus increased as shown in Fig. 1. The confining pressure $\left(f_{l}\right)$ can be estimated as follows:

$$
f_{l}=k_{\varepsilon} \frac{2 f_{f r p} t}{d}
$$

where $f_{f r p}$ and $t$ are the tensile strength and the thickness of FRP, respectively; $d$ is the diameter of the column; and $k_{\varepsilon}$ is the FRP efficiency factor which was defined by Harries and Carey (2003). The FRP efficiency factor is the ratio between the actual rupture strain of FRP in concrete columns and the rupture strain of FRP from flat coupon tests. This study adopts a 
simple and considerably accurate model by Lam and Teng (2003) to estimate the compressive strength of FRP-confined concrete:

$$
\frac{f_{c c}^{\prime}}{f_{c o}^{\prime}}=1+3.3 \frac{f_{l}}{f_{c o}^{\prime}}
$$

where $f_{c c}^{\prime}$ and $f_{c o}^{\prime}$ are the compressive strengths of confined and unconfined concrete, respectively.

\section{Confinement effect in impact loads}

The compressive strength of FRP-confined concrete under static loads can be calculated with the above equations. There has been no model to calculate the compressive strength of FRPconfined concrete against impact loads in the open literature, in which two possible confinement effects need to be studied. Under axial impact loads, FRP-confined concrete tends to expand laterally but the confining pressure from the FRP prevents the expansion thus increases the specimen's capacity. This confinement mechanism is similar to that under static loads. In such cases, the rupture strain of the FRP under impact loads is crucial but it has not been well studied yet. In addition, when a projectile impacts a specimen, the concrete tends to expand laterally with an acceleration, which causes the inertial force as a confinement pressure (Hao and Hao 2014). The axial capacity of the specimen thus increases by multiple confinement effects as shown in Fig. 1. Studies of lateral inertial confinement effect on concrete specimens under impact loads have been reported in the study by Hao and Hao (2014). No study of the lateral inertial confinement effect of FRP wrapped concrete specimen under impact load has been reported yet. Since FRP wraps may change the lateral expansion acceleration of concrete specimen under impact loads, the lateral inertial confinement effect of FRP confined concrete specimen will be different from that of unconfined concrete specimens. Analyzing the confined 
111 strength of these specimens is thus difficult because of its complexity. This study focuses on

112 the contribution of FRP to the confinement effect of FRP-confined concrete against impact.

113 In general, the dynamic tensile strength of FRP needs to be considered to determine the

114 confining pressure under impact loads. Al-Zubaidy et al. (2013) reported an experimental

115 testing on FRP and proposed an empirical equation to determine the dynamic tensile strength

116 as follows:

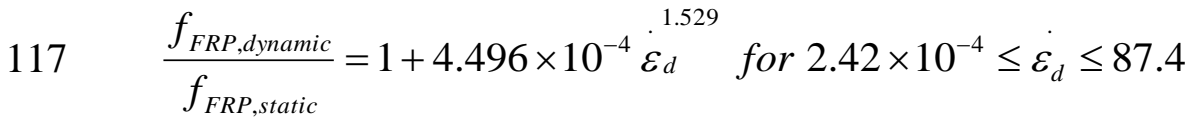

118 where $\varepsilon_{d}$ is the strain rate corresponding to the dynamic tensile strength $\left(f_{R P, d y n a m i c}\right)$, and

$119 f_{R P, \text { dynamic }}$ and $f_{R P, \text { dynamic }}$ are the dynamic and static tensile strength of FRP, respectively. If the

120 strain rate of 15 is assumed, which is quite large corresponding to the cases in this study as

121 reported in Table 2, the dynamic tensile strength of FRP is equal to 1.0283 of the static tensile

122 strength. The increase in the tensile strength of FRP in this study is therefore in general less

123 than $2.8 \%$. Since the strain rate of a specimen significantly changes with time during an impact

124 event and can be far lower than 15 , it is reasonable to ignore the dynamic tensile strength

125 increment of FRP in this study (low impact velocity). However, it should be noted that the

126 dynamic tensile strength of FRP may significantly increase in cases of blast loads or high

127 velocity impacts, where the strain rate can reach a few hundred or higher. In such cases the

128 strain rate effect should not be neglected.

129 Experimental program

130 Test matrix and materials' properties

131 Concrete cylinders were cast and tested until failure under drop-weight tests. The cylinders

132 were $100 \mathrm{~mm}$ in diameter and $200 \mathrm{~mm}$ in height. The compressive strength of concrete was 46 
MPa at 28 day age. These cylinders wrapped with Carbon FRP (CFRP) and Glass FRP (GFRP)

134 of different schemes representing heavy confinement, sufficient confinement and insufficient

135 confinement as shown in Fig. 2. Details of the specimens and testing results are presented in

136 Table 1. For easy reference, names of the concrete cylinders include three parts: the first part is

137 Letter $\mathrm{C}$ and $\mathrm{G}$ stating the type of fiber. The second part indicates the wrapping arrangement

138 and a number of FRP layers in which $\mathrm{F}$ is for fully wrapping while $\mathrm{P}$ is for partially wrapping

139 with a gap of $50 \mathrm{~mm}$ between FRP strips. The third part refers to drop height at which the

140 projectile will be released. For instance, Cylinder CF1-2 means this specimen is fully wrapped

141 with one CFRP layer and is tested under $2 \mathrm{~m}$ drop height. The wrapping arrangement and

142 specimens' names are illustrated in Fig. 2. If a specimen does not fail in the first drop, it will

143 be repeatedly tested under the same drop height until failure. The name of these specimens will

144 be added one more number in a bracket to indicate the number of drops until failure occurs as

145 shown in Table 1.

146 FRP was bonded to the substrate of concrete by epoxy resin which has a tensile strength of 54

$147 \mathrm{MPa}$, tensile modulus of $2.8 \mathrm{GPa}$, and 3.4\% tensile elongation (West System n.d. 2015). The

148 adhesive used was a mixture of epoxy resin and hardener at 5:1 ratio. Before the first layer of

149 FRP was attached, the adhesive was spread onto the specimen's surface and FRP was attached

150 to the surface. After the first ring, the adhesive was spread onto the surface of the first FRP

151 layer and the second layer was continuously bonded, ensuring that 100-mm overlap was

152 maintained.

153 The FRPs are the same types from the same supplier used in a number of previous studies (Hadi 154 et al. 2013; Pham et al. 2013). In these studies, at least five CFRP coupons were fabricated and 155 tested according to ASTM D3039 (2008). The CFRP used was $75 \mathrm{~mm}$ in width with a 156 unidirectional fiber density of $340 \mathrm{~g} / \mathrm{m}^{2}$. The nominal thickness of CFRP was $0.45 \mathrm{~mm}$ and the 
tensile strength was $1548 \mathrm{MPa}$. The average strain at the maximum tensile force and the average

158 elastic modulus were $1.74 \%$ and $89 \mathrm{GPa}$, respectively. The GFRP used was $50 \mathrm{~mm}$ in width with a unidirectional fiber density of $440 \mathrm{~g} / \mathrm{m}^{2}$. The nominal thickness of GFRP was $0.35 \mathrm{~mm}$ and the tensile strength was $833 \mathrm{MPa}$. The average strain at the maximum tensile force and the average elastic modulus were $1.97 \%$ and $41 \mathrm{GPa}$, respectively.

In order to measure the lateral strain of FRP wraps and the axial strain of the specimens, strain gauges are attached to three different positions which are top, middle and bottom of the of the overlap zone of FRP wraps.

\section{Impact Testing Procedure}

Drop-weight impact tests were conducted by dropping a weight from a certain height onto the top of the cylinders using the impact test apparatus, as shown in Fig. 3. The weight was made of a solid steel cylinder, weighing $97.5 \mathrm{~kg}$. It is worth mentioning that the shape of the impactor plays an important role to the impact force and the impact contact thus it was designed to have a smooth flat bottom with a radius $r=50 \mathrm{~mm}$. A plastic guiding tube was utilized to ensure the impactor falling vertically to the targets. A load cell was placed at the bottom of the specimens to measure the impact force. A high-speed camera which was set to capture 50400 frames per

174 second was used to monitor the failure processes. This frame rate was set after a few trials with 175 lower frame rate which was not fast enough to capture the very short impact events (about 1

176 millisecond, ms). The data acquisition system controlled by a computer was used to record 177 signals from the load cell and strain gauges. The data acquisition system recorded data at a 178 sampling rate of $1 \mathrm{MHz}$. 
The impact events occurred in a very short period of time (about $1 \mathrm{~ms}$ ) so that the data

181 acquisition system needs to setup at a sufficiently high sampling rate to properly record the

182 testing data. Different sampling rates were tried to investigate the effect the sampling rate on

183 recording the impact force. Three different sampling rates were used in this investigation

184 including $20 \mathrm{kHz}, 100 \mathrm{kHz}$ and $1 \mathrm{MHz}$. The impact forces of identical unconfined concrete

185 cylinders were recorded by these sampling rates and plotted in Fig. 4. It can be seen that at the

186 sampling rate of $20 \mathrm{kHz}$ the data acquisition system captured the maximum impact force of

187 about $60 \mathrm{kN}$. This impact force was even smaller than that under quasi-static load, which was

$188361 \mathrm{kN}$. Although the test with $100 \mathrm{kHz}$ sampling rate recorded a higher impact force $(350 \mathrm{kN})$

189 as compared to the one with $20 \mathrm{kHz}$, the impact force is still smaller than the static force,

190 indicating that the sampling rate is insufficient. Meanwhile, the sampling rate of $1 \mathrm{MHz}$

191 recorded much higher impact force $(550 \mathrm{kN})$ and much more data points. Based on this

192 experiment, impact force measured with a sampling rate less than $100 \mathrm{kHz}$ did not yield

193 accurate results. The data acquisition system was thus set at the sampling rate of $1 \mathrm{MHz}$.

194 Experimental results of dynamic tests

195 Failure modes and Crack patterns

196 In order to eliminate the end friction effect, grease was applied on both ends of the tested

197 specimens. The progressive failure of the tested specimens was monitored by the high-speed

198 camera. The failure modes are divided into three different types including splitting failure of

199 unconfined concrete, FRP fracture of the confined specimens, and failure at unconfined

200 concrete regions of the partially confined specimens. The splitting failure mode of the

201 unconfined concrete specimens indicates that friction at the specimens' ends was negligible as

202 shown in Fig. 5. Small cracks were observed at the impact end at a very early stage (0.04 ms)

203 after the projectile in contact with the specimen. Afterward, the splitting crack initiated at about 
$0.4 \mathrm{~ms}$ after the impact event. This splitting crack took about another $0.4 \mathrm{~ms}$ to propagate from

205 the top to the end of the specimen. This splitting crack and crushing failure at the impact end dominated the failure mode of unconfined concrete. Meanwhile, the confined concrete specimens failed by rupture of the FRP jacket. A visible crack initiated at the impact end at about $0.22 \mathrm{~ms}$ and then propagated downward reaching the midheight at about $1 \mathrm{~ms}$ as shown in Fig. 6. It should be noted that only when the crack is wide enough it changes the color of the

210 FRP jacket and can then be seen in the high-speed images. Smaller cracks on FRP jacket that 211 could be formed before $0.22 \mathrm{~ms}$ are not able to be seen. The visible crack stopped propagating to the bottom of the specimen but developed in the hoop direction at about the midheight of the specimen. The FRP jacket was then tore off leading to a complete collapse of the specimen. In this study, all the fully confined specimens that failed at the first drop exhibited a consistent progressive failure at which cracks propagated from the impact end downward to the midheight.

In another hand, specimens which did not fail at the first drop might show the failure occurring at the mid height region of the specimens. This change in the failure mode can be explained by the lateral confinement effect. As the projectile impacts a specimen, it generates stress waves propagating axially from the top to the bottom of the specimen. If the stress waves are strong enough, they damage the specimen immediately. In such cases, the damage initiates at the top and propagates to the bottom. The compressive stresses in these specimens are not uniform before the damage of the specimen. However, if the stress waves are not strong enough to destroy the specimens immediately, they propagate forth and back in the specimen and make the compressive stresses approximately uniform after a few reflections (Davies and Hunter 1963). Once the compressive stresses are uniform, the failure mode of the specimens is expected to be similar to that under static tests. In static tests, the friction force at the ends of concrete cylinders confines the specimen's ends. The cylinders usually fail at the weaker region which is at the midheight of the specimens. Therefore, when the compressive stresses in a 
concrete cylinder are approximately uniform, it likely fails at the midheight because of the

230 minimum end friction confinement in this region. This observation can also be used to explain

231 the different failure modes presented in previous studies (Shan et al. 2007; Uddin et al. 2008;

232 Xiao and Shen 2012). In general, if the high impact energy generated stress waves are intensive 233 enough to destroy the concrete matrix and the FRP jacket upon impact, the failure at the top of 234 specimens is usually observed as reported in the studies (Shan et al. 2007; Xiao and Shen 2012).

235 This failure mode usually occurs in split Hopkinson pressure bar and gas gun tests when a specimen fails without uniform stresses along its length (Hao et al. 2010). Otherwise, when the stress waves are not strong enough to damage a specimen at the first drop and multiple stress wave reflections uniform the stress state in the specimen, the specimen is likely to fail at mid height of the specimen because of the minimum end friction confinement. Similar observations were also reported by Uddin et al. (2008). Fig. 7 describes the failure propagation in the tested specimens.

Partially confined specimens always fail at the regions of unconfined concrete as shown in Fig.

8. As can be seen from this figure, when the high intensive stress waves came, the concrete inside the top FRP ring cracked but was confined by the FRP ring. The partial damage of the FRP ring changed the FRP color which can be seen more clearly on a video than images. The stress wave even caused some cracks on the top FRP ring but this region did not fail. These stress waves then propagated downward to the lower regions and destroyed the weaker regions with the unconfined concrete. These specimens are relatively weaker than the fully confined concrete so that they could not resist much stress. Stress wave traveled pass through the specimen in a shorter time period. Cracks propagated from the impact end to the bottom of the specimens within about $0.5 \mathrm{~ms}$. The specimens finally failed by fracture and spalling out of unconfined concrete. There were two unconfined concrete regions in partially confined 
254 while lower one led to only the bottom unconfined concrete region being damaged as evident 255 by Specimen GP2_1.5 in Fig. 9a.

256 The failure surface of the tested specimens was also investigated. Specimens with weak 257 confining pressure showed an inclined failure surface as Specimen CF1_2.5 shown in Fig. 9b. 258 If a specimen is heavily confined by ductile FRP (GFRP), GFRP rupture was not observed 259 therefore no obvious failure of the specimen was observed although the concrete core 260 completely failed. Fig. 9c shows the complete failure of the concrete core of Specimen GF3_3.5 261 after GFRP was cut. It is worth noting that although specimens CF2 have higher confining pressure than specimens GF3 in static analysis, an inclined failure surface was still observed on specimens CF2 because of the FRP rupture. This is because CFRP is more brittle than GFRP so that it could not effectively confine the concrete core under impact loads. These observations indicate the relatively ductile GFRP can better enhance the impact resistant capacity of confined concrete than the more brittle CFRP.

\section{Impact resistance}

268 In the two most relevant studies discussed in the introduction the position of the load cell is not 269 given (Shan et al. 2007; Xiao and Shen 2012). Meanwhile, Uddin et al. (2008) measured the 270 impact force by a load cell embedded in the projectile, which monitors the force at the impact 271 end. When a projectile impacts a specimen, a part of the impact energy is to accelerate the 272 specimen, which generates inertia force. If the impact force is measured from the impact end 273 of the specimen, it is equal to the sum of the impact resistance of the specimen plus the inertia resistance. It is obvious that the forces at the impact end and the bottom end of the specimen 275 are not identical (Rieder and Mindess 1998). As discussed in the study by Bischoff and Perry 276 (1991) in such tests the impact force should be measured by placing load cell at the bottom of 277 the specimen. This load cell arrangement has been followed in many impact tests, e.g. (Xu et 
al. 2012). The impact force of the tested specimen in this study was therefore measured by the load cell placed at the bottom end of the specimens.

The time histories of the impact force of the unconfined concrete specimens are presented in

281 Fig. 10 and the corresponding testing conditions are defined in Table 1. The impact force of the unconfined concrete specimens increased with the impact energy. The impact force of Specimen R_2 was $565 \mathrm{kN}$ as compared to the corresponding static load of $361 \mathrm{kN}$. The time 284 history of the impact force was not a simple shape but a zigzag curve. The impact forces of unconfined concrete specimens serve as a reference to examine the effectiveness of the confined concrete. Fig. 11 shows the time history of the impact force of CFRP-confined concrete specimens. The CFRP-confined concrete group had 6 specimens as stated in Table 1 but some experimental results were unfortunately lost owing to malfunctioning of the recording system during the impact. As mentioned previously, the required sampling rate of this experimental program is very high $(1 \mathrm{MHz})$ so that it limited the recording duration of the data acquisition system at about 1s. The maximum impact force of Specimen CF2_2.5(2) was $952 \mathrm{kN}$ with an impact duration of $1.8 \mathrm{~ms}$. From the experimental results, it can be observed that heavier confined specimens resisted higher impact energy and thus resisted higher impact force and 294 longer impact duration. Specimen CF1_2.5(2) was tested under the same impact energy used 295 for Specimen CF2_2.5(2) but showed lower impact force and shorter impact duration. 296 Accordingly, the impulse of the impact force of Specimen CF2_2.5(2) was higher than that of 297 Specimen CF1_2.5(2). Specimen CF1_2.5(2) experienced more severe damage than Specimen 298 CF2_2.5(2). It means that higher percentage of the impact energy was transferred to damage 299 Specimen CF1_2.5(2) than Specimen CF2_2.5(2). This observation shows that an increase in 300 FRP layers leads to enhancement on the impact resistance. In addition, the time histories of the 301 impact force of GFRP confined concrete specimens are presented in Fig. 12. It is again confirmed that higher impact energy yields higher impact force, for example, Specimens 
GF2_2, GF2_2.5, and GF2_3 were identical but they yielded different impact forces of $772 \mathrm{kN}$,

$304782 \mathrm{kN}$, and $1024 \mathrm{kN}$, respectively. GFRP confined concrete was found to be much more 305 efficient than CFRP-confined concrete because GFRP was ruptured at a much higher strain than 306 those of CFRP, which is further discussed in the subsequent section.

\section{Discussion}

\section{Rupture strain of FRP}

As previously mentioned, FRP strain was monitored by a number of strain gauges attached along the specimens. Fig. 13 presents the FRP strain of Specimens CF2_2.5 and GF3_2.5.

311 These specimens did not fail at the first impact but exhibited some minor cracks on the FRP jackets. Therefore, the FRP strain of these specimens was close to the rupture strain of FRP. In Specimen CF2_2.5, SGs 1 and 2 had identical maximum and residual values which were of about $0.24 \%$ and $0.09 \%$, respectively. The FRP strain at SG 3 reached the maximum value of about $0.17 \%$ with the residual strain of $0.05 \%$. Meanwhile, SGs 1, 2, and 3 of Specimen GF3_2.5 reached the maximum values of $0.98 \%, 0.52 \%$, and $0.28 \%$, respectively. The residual strain of FRP at the impact end of the specimen (SG 1) was quite large at about $0.67 \%$. As can be seen GFRP-confined concrete had large residual strain than that of CFRP-confined concrete, showing that the first one was able to absorb more impact energy than the later one. It is worth mentioning that Specimen CF2_2.5 is expected to yield at the static capacity of $737 \mathrm{kN}$ while 321 the corresponding of Specimen GF3_2.5 at a relatively small value of $593 \mathrm{kN}$. Although the mechanical properties of GFRP are not as good as those of CFRP under the static loading condition GFRP showed better performance against impact loads because it is more ductile than CFRP. GFRP is thus highly recommended for impact resistance than CFRP. In addition, the peak values of Strain Gauges 1, 2, and 3 from the specimens in Fig. 13 are different and reduce

326 from the impact end to the bottom end. It means that the lateral confining pressure was not 
uniform along the specimens. This observation implies the compressive stresses in these specimens were not uniform along their longitudinal axes.

In order to take a closer examination of the rupture strain of FRP, its strain in specimens at which the failure exactly occurred at the strain gauges is presented in Fig. 14. Specimen CF1_2.5(2) failed owing to FRP rupture at the impact end so that the FRP strain of SG 1 was the rupture strain. By the same reason, FRP strain of SG 1 in Specimen GF1_2 was the rupture strain. The rupture strain of FRP of Specimens CF1_2.5(2) and GF1_2 was 0.37\% and 1.30\%, respectively. If these specimens had been tested under static loading, they would have yielded at the rupture strain of $0.96 \%$ and $1.08 \%$, respectively. If the strain efficiency factor of 0.55 is assumed, which means that the fiber in the specimens ruptures at $55 \%$ of the maximum rupture strain from flat coupon tests (ACI 440.2R-08 2008). The very low maximum strain as compared to that in static $(0.96 \%)$ shows that the CFRP is very brittle under impact. It can be seen that the maximum strain of GFRP was close to the rupture strain recommended by ACI 440.2R-08 340 (2008). The maximum strain of FRP of all the tested specimens was examined and summarized in Table 1. It should be noted that the axial strain could not be monitored by SG 4 axially bonded 342 to the specimens. The experimental results showed that the reading from SG 4 was either equal 343 to zero or very small (about $<0.05 \%$ ).

\section{FRP efficiency factor}

345 It is well known that the FRP jacket in confined specimens may rupture at a strain far lower 346 than its rupture strain determined from flat coupon tests (Harries and Carey 2003; ACI 440.2R34708 2008; Pham et al. 2015b). The FRP efficiency factor $\left(k_{\varepsilon}\right)$ is normally used to quantify this 348 phenomenon. Experimental results from static tests have shown that the FRP efficiency factor 349 varied from $0.4-0.7$ as presented by Pham and Hadi (2014). The FRP efficiency factor was 350 also found much higher than 0.7, e.g. up to 0.94 for CFRP and 0.91 for GFRP (Pham et al. 
352 factor. This factor is significantly scattered due to many reasons, for example, section geometry, deficiency of concrete surface, misalignment of FRP, uneven tension during wrapping, and

354 brittleness of FRP. In addition, high loading rate associated with impact may change the failure 355 mechanism of FRP leading to different rupture strains. The rupture strain and the FRP 356 efficiency factor were calculated from the experimental results and summarized in Table 2.

357 As can be seen the FRP efficiency factor under impact is lower than that under static loading.

358 It means that FRP performances under impact loads are not as good as under static loads. The 359 FRP efficiency factor of CFRP under impact was very low, ranging from 0.14 to 0.21 . These

360 values are significantly lower than that under static loads. Meanwhile, the FRP efficiency factor 361 of GFRP under impact ranged from 0.5 to 0.66 . Even though these values are smaller than those

362 in static, the better performance of GFRP versus CFRP under impact is again confirmed. Based 363 on the experimental results, the efficiency factor of FRP is proposed as 0.18 and 0.56 for CFRP 364 and GFRP, respectively.

\section{Impact resistance}

366 As previously mentioned, the impact resistance of FRP-confined concrete includes the 367 confinement effects from the FRP jacket and lateral inertia. The lateral inertia confinement 368 exists in both unconfined concrete and confined concrete so that the actual contribution of the 369 confinement effect from FRP can be estimated by subtracting the impact resistance of 370 unconfined specimens from the corresponding confined specimens. The confined concrete 371 strength against impact can be estimated as follows: 
373 where $f_{d}$ is the dynamic concrete strength which included strain rate and lateral inertia effects,

$374 k$ is the confinement efficiency factor calibrated against experimental data, and $f_{l}$ is calculated

375 from Equation 1. The dynamic concrete strength can be experimentally derived from the impact

376 force of the unconfined concrete specimens. Since the confinement efficiency factor has not

377 been proposed for impact loading condition yet, the value of 3.3 for static is adopted in this

378 study. If the FRP efficiency factor $\left(k_{\varepsilon}\right)$ of 0.55 is adopted, the FRP confinement effect is

379 presented in Fig. 15. In such cases, it seems that the model recommended by ACI 440.2R-08

380 (2008) still can predict the FRP confinement effect very well for CFRP but not GFRP. This

381 calculation was based on the assumption of the FRP efficiency factor $\left(k_{\varepsilon}\right)$ is equal to 0.55 for

382 both CFRP and GFRP. However, the actual FRP efficiency factor reported in Table 2 is far

383 different from the assumption. If the actual values are used to predict the confined concrete

384 strength, results are presented in Fig. 16. From the figure, there is a considerable difference

385 between the prediction and experiment so that the model in ACI 440.2R-08 (2008) proposed

386 for static loads should not be used for impact loads.

387 A widely used form of confinement model (Richart et al. 1928) was adopted to express the 388 confinement effect of FRP-confined concrete under axial impact in which new dynamic 389 confinement coefficients were suggested. It is noted that this proposed model is derived on 390 small scale testing with normal-strength concrete so that it has not been evaluated against large 391 scale specimens or high-strength concrete. This model is also applicable for the impact velocity 392 less than $7.7 \mathrm{~m}$. The proposed model is given as follows: 


$$
f_{c c}^{\prime}=f_{d}+k f_{l} \quad\left\{\begin{array}{l}
k=10.8 \text { for } C F R P \\
k=7.9 \text { for } G F R P
\end{array}\right\}
$$

394 where $f_{d}$ is the dynamic concrete strength which can be calculated from the study by Hao and 395 Hao (2014) or experimentally derived from the impact tests of the unconfined concrete 396 specimens. The performance of the proposed model is presented in Fig. 17 showing predictions 397 with reasonable accuracy. It is noted that the dynamic concrete strength can be estimated by 398 using the dynamic increase factor (DIF) and the strain rate. Hao and Hao (2014) proposed a new DIF relations, in which the lateral inertial confinement effect was removed to provide more reliable prediction, to determine the dynamic concrete strength as follows:

401

$$
\begin{aligned}
& D I F=\frac{f_{d}}{f_{c o}^{\prime}}=0.0419\left(\log \dot{\varepsilon}_{d}\right)+1.2165 \text { for } \dot{\varepsilon}_{d} \leq 30 / s \\
& D I F=\frac{f_{d}}{f_{c o}^{\prime}}=0.08988\left(\log \dot{\varepsilon}_{d}\right)^{2}-2.8255\left(\log \dot{\varepsilon}_{d}\right)+3.4907 \text { for } \dot{\varepsilon}_{d}>30 / s
\end{aligned}
$$

402 where $\varepsilon_{d}$ is the strain rate corresponding to the dynamic concrete strength $\left(f_{d}\right)$. It is assumed 403 that the strain rate of unconfined concrete at the drop height of $1.5 \mathrm{~m}$ is equal to 15 , which is 404 the same of the strain rate of FRP close at the impact of confined specimen at the first drop. 405 From Equation 6, the DIF is equal to 1.31 which leads to the dynamic concrete strength of 60.3 $406 \mathrm{MPa}$. Since the dynamic concrete strength derived from Specimen R1.5 was $63.2 \mathrm{MPa}$, it is 407 reasonable to use this model to predict the dynamic concrete strength.

\section{Conclusions}

409 This study examines the confinement mechanism of FRP confined concrete against impact 410 loads. The findings in this study can be summarized as follows: 
411 1. FRP can be used to strengthen concrete columns against impact loads. The confinement

412 efficiency significantly depends on the ductility of the jacket such as high rupture strain.

413 2. Different failure modes of FRP-confined concrete under impact were observed, which are 414 dependent on confining pressure, wrapping schemes, and impact energy.

415 3. FRP-confined concrete fails progressively from top to the bottom if the specimen is 416 damaged at the first drop. Failure at the midheight may be observed if the specimen fails 417 by multiple drops.

418 4. The FRP rupture strain under impact is significantly lower than that under static loads so 419 that the common FRP efficiency factor of 0.55 is inapplicable in this case. The actual FRP rupture strain needs to be taken into account to predict the axial impact resistance.

421 5. GFRP performs much better than CFRP in resisting impact loads because the first one has high rupture strain than the later one. GFRP is thus highly recommended for impact strengthening.

6. The sampling rate of about $1 \mathrm{MHz}$ is essential to achieve accurate results. Lower sampling rate may yield inaccurate recordings.

426 Finally, a confinement model for impact loads was proposed to predict the impact resistance of 427 FRP-confined concrete. It is recommended that further studies should be conducted to 428 systematically examine the effects of FRP efficiency factor and strain rate on the confinement 429 mechanism of FRP-confined concrete. 
The authors would like to acknowledge the technical support from Mr. Jim Walters from the

432

University of Western Australia and Messrs Arne Bredin, Mick Ellis, Ashley Hughes, Luke

English, Craig Gwyther, and Rob Walker from Curtin University.

435

436

437

438

439

440

441

442

443

444

445

446

447

448

449

450

451

452

453

454

455

456

457

458

459

460

461

462

463

464

465

466

467

468

469

470

471

472

473

474

\section{References}

ACI 440.2R-08 (2008). "Guide for the Design and Construction of Externally Bonded FRP Systems for Strengthening Concrete Structures." 440.2R-08, American Concrete Institute, Farmington Hills, MI.

Al-Zubaidy, H., Zhao, X.-L., and Al-Mahaidi, R. (2013). "Mechanical characterisation of the dynamic tensile properties of CFRP sheet and adhesive at medium strain rates." Composite Structures, 96, 153-164.

ASTM D3039 (2008). "Standard Test Method for Tensile Properties of Polymer Matrix Composite Materials." D3039:2008West Conshohocken, PA.

Bischoff, P. H., and Perry, S. H. (1991). "Compressive behaviour of concrete at high strain rates." Materials and Structures, 24(6), 425-450.

Cusson, D., and Paultre, P. (1995). "Stress-Strain Model for Confined High-Strength Concrete." Journal of Structural Engineering, 121(3), 468-477.

Davies, E. D. H., and Hunter, S. C. (1963). "The dynamic compression testing of solids by the method of the split Hopkinson pressure bar." Journal of the Mechanics and Physics of Solids, 11(3), 155-179.

Hadi, M. N. S., Pham, T. M., and Lei, X. (2013). "New Method of Strengthening Reinforced Concrete Square Columns by Circularizing and Wrapping with Fiber-Reinforced Polymer or Steel Straps." Journal of Composites for Construction, 17(2), 229-238.

Hao, Y., Hao, H., and Li, Z.-X. (2010). "Numerical analysis of lateral inertial confinement effects on impact test of concrete compressive material properties." International Journal of Protective Structures, 1(1), 145-168.

Hao, Y., and Hao, H. (2014). "Influence of the concrete DIF model on the numerical predictions of RC wall responses to blast loadings." Engineering Structures, 73, 24-38.

Harries, K. A., and Carey, S. A. (2003). "Shape and "gap" effects on the behavior of variably confined concrete." Cement and Concrete Research, 33(6), 881-890.

Lam, L., and Teng, J. G. (2002). "Strength models for fiber-reinforced plastic-confined concrete." Journal of Structural Engineering, 128(5), 612-623.

Lam, L., and Teng, J. G. (2003). "Design-oriented stress-strain model for FRP-confined concrete." Construction and Building Materials, 17(6-7), 471-489.

Mutalib, A. A., and Hao, H. (2011a). "Development of P-I diagrams for FRP strengthened RC columns." International Journal of Impact Engineering, 38(5), 290-304.

Mutalib, A. A., and Hao, H. (2011b). "Numerical Analysis of FRP-Composite-Strengthened RC Panels with Anchorages against Blast Loads." Journal of Performance of Constructed Facilities, 25(5), 360-372.

Pham, T. M., Doan, L. V., and Hadi, M. N. S. (2013). "Strengthening square reinforced concrete columns by circularisation and FRP confinement." Construction and Building Materials, 49, 490-499.

Pham, T. M., and Hadi, M. N. S. (2014). "Predicting Stress and Strain of FRP Confined Rectangular/Square Columns Using Artificial Neural Networks." Journal of Composites for Construction, 18(6), 04014019. 
Pham, T. M., Hadi, M. N. S., and Tran, T. M. (2015a). "Maximum usable strain of FRPconfined concrete." Construction and Building Materials, 83, 119-127.

Pham, T. M., Hadi, M. N. S., and Youssef, J. (2015b). "Optimized FRP Wrapping Schemes for Circular Concrete Columns." Journal of Composites for Construction, 19(6), 04015015.

Pham, T. M., and Hao, H. (2016a). "Review of Concrete Structures Strengthened with FRP against Impact Loads." Structures, 7, 59-70.

Pham, T. M., and Hao, H. (2016b). "Impact Behavior of FRP-Strengthened RC Beams without Stirrups." Journal of Composites for Construction, DOI: 10.1061/(ASCE)CC.19435614.0000671, 04016011.

Richart, F. E., Brandtzaeg, A., and Brown, R. L. (1928). "A study of the failure of concrete under combined compressive stress." Bulletin 1985, Univ. of Illinois Engineering Experimental Station, Champaign, III.

Rieder, K.-A., and Mindess, S. (1998). "New test method to evaluate the impact behaviour of biaxially confined concrete." Materials and Structures, 31(10), 669-675.

Shan, J. H., Chen, R., Zhang, W. X., Xiao, Y., and Lu, F. Y. (2007). "Behavior of Concrete Filled Tubes and Confined Concrete Filled Tubes under High Speed Impact." Advances in Structural Engineering, 10(2), 209-218.

Spoelstra, M. R., and Monti, G. (1999). "FRP-Confined Concrete Model." Journal of Composites for Construction, 3(3), 143.

Uddin, N., Purdue, J. D., and Vaidya, U. (2008). "Feasibility of thermoplastic composite jackets for bridge impact protection." Journal of Aerospace Engineering, 21(4), 259-265.

West System n.d. (2015). "Epoxy resins and hardeners - Physical properties." <http://www.westsystem.com/ss/typical-physical-properties $>$. (Jan. 31, 2015).

Wu, Y. F., and Zhou, Y. W. (2010). "Unified Strength Model Based on Hoek-Brown Failure Criterion for Circular and Square Concrete Columns Confined by FRP." Journal of Composites for Construction, 14(2), 175-184.

Xiao, Y., and Shen, Y. (2012). "Impact Behaviors of CFT and CFRP Confined CFT Stub Columns." Journal of Composites for Construction, 16(6), 662-670.

$\mathrm{Xu}, \mathrm{Z}$., Hao, H., and Li, H. N. (2012). "Experimental study of dynamic compressive properties of fibre reinforced concrete material with different fibres." Materials \& Design, 33, 4255. 
$507 \quad$ List of Figures

508 Figure 1. Confinement mechanism under impact

509 Figure 2. Wrapping arrangement and specimen design

510 Figure 3. Drop-weight test apparatus

511 Figure 4. Sampling rate effect

512 Figure 5. Progressive failure of unconfined concrete

513 Figure 6. Progressive failure of fully confined concrete

514 Figure 7. Failure propagation

515 Figure 8. Progressive failure of partially confined concrete

516 Figure 9. Failure surface

517 Figure 10. Time history of impact force (unconfined concrete)

518 Figure 11. Time history of impact force (CFRP-confined concrete)

519 Figure 12. Time history of impact force (GFRP-confined concrete)

520 Figure 13. Time history of FRP strain

521 Figure 14. Time history of FRP rupture strain

522 Figure 15. FRP confinement effect $\left(k_{\varepsilon}=0.55\right)$

523 Figure 16. FRP confinement effect $\left(k_{\varepsilon}=0.18\right.$ and 0.56 for CFRP and GFRP, respectively)

524 Figure 17. Performance of the proposed model 
$525 \quad$ List of Tables

526 Table 1. Text matrix

527 Table 2. FRP efficiency factor and strain rate 
Table 1. Test matrix

\begin{tabular}{|c|c|c|c|c|c|c|}
\hline Specimen & $\begin{array}{c}\text { Number of FRP } \\
\text { layers }\end{array}$ & $\begin{array}{l}\text { Drop } \\
\text { height } \\
(\mathrm{m})\end{array}$ & $\begin{array}{l}\text { Theoretical } \\
\text { estimation - } \\
\text { static }(\mathrm{kN})\end{array}$ & $\begin{array}{c}\text { Experimental } \\
\text { impact results } \\
(\mathrm{kN})\end{array}$ & $\begin{array}{l}\text { Impact } \\
\text { duration } \\
(\mathrm{ms})\end{array}$ & $\begin{array}{l}\text { FRP strain } \\
\text { at SG } 1(\%)\end{array}$ \\
\hline $\mathrm{R}-1$ & & 1 & & 406 & 0.9 & - \\
\hline $\mathrm{R}-1.5$ & - & 1.5 & 361 & 496 & 0.9 & - \\
\hline $\mathrm{R}-2$ & & 2 & & 565 & 0.6 & - \\
\hline CF1-1.5 & \multirow{4}{*}{1 CFRP layer } & 1.5 & \multirow{4}{*}{546} & 651 & 1.4 & 0.45 \\
\hline CF1-2 & & 2 & & \# & $\#$ & $\#$ \\
\hline CF1-2.5 & & 2.5 & & $\#$ & $\#$ & $\#$ \\
\hline CF1-2.5(2) & & 2.5 & & 756 & 1 & 0.37 \\
\hline CF2-2 & \multirow{4}{*}{2 CFRP layers } & 2 & \multirow{4}{*}{737} & $\#$ & $\#$ & $\#$ \\
\hline CF2-2.5 & & 2.5 & & 915 & 2.1 & 0.24 \\
\hline $\mathrm{CF} 2-2.5(2)$ & & 2.5 & & 952 & 1.8 & 0.35 \\
\hline CF2-3 & & 3 & & $\#$ & $\#$ & $\#$ \\
\hline GF1-1.5 & \multirow{3}{*}{1 GFRP layer } & 1.5 & \multirow{3}{*}{434} & $\#$ & $\#$ & $\#$ \\
\hline GF1-2 & & 2 & & 993 & 1 & 1.30 \\
\hline GF1-2.5 & & 2.5 & & $\#$ & $\#$ & $\#$ \\
\hline GF2-2 & \multirow{5}{*}{2 GFRP layers } & 2 & \multirow{5}{*}{513} & $\#$ & $\#$ & $\#$ \\
\hline GF2-2(2) & & 2 & & $\#$ & $\#$ & $\#$ \\
\hline GF2-2(3) & & 2 & & 772 & 1.2 & 0.70 \\
\hline GF2-2.5 & & 2.5 & & 872 & 1.6 & 1.35 \\
\hline GF2-3 & & 3 & & 1024 & 1.1 & $0.52^{*}$ \\
\hline GF3-2.5 & \multirow{9}{*}{3 GFRP layers } & 2.5 & \multirow{9}{*}{593} & 952 & 1.9 & $0.98 / 0.67^{* * *}$ \\
\hline GF3-2.5(2) & & 2.5 & & 1035 & 1.9 & $0.27 / 0.05^{* *}$ \\
\hline GF3-2.5(3) & & 2.5 & & 1089 & 2 & $0.26 / 0.04^{* *}$ \\
\hline GF3-2.5(4) & & 2.5 & & 833 & 2.5 & 0.38 \\
\hline GF3-3 & & 3 & & 1202 & 2.4 & 1.00 \\
\hline GF3-3(2) & & 3 & & 1010 & 2.4 & $\#$ \\
\hline GF3-3(3) & & 3 & & 878 & 1.5 & $\#$ \\
\hline GF3-3.5 & & 3.5 & & 1021 & 2.7 & $1.03 / 0.65^{* *}$ \\
\hline GF3-3.5(2) & & 3.5 & & 964 & 2.9 & 0.25 \\
\hline GP2-1.5 & \multirow{3}{*}{2 GFRP layers } & 1.5 & \multirow{3}{*}{406} & $\#$ & $\#$ & $\#$ \\
\hline GP2-2 & & 2 & & 665 & 1.3 & $\#$ \\
\hline GP2-2.5 & & 2.5 & & 639 & 0.8 & $0.52 / 0.22$ \\
\hline GP3-1.5 & \multirow{3}{*}{3 GFRP layers } & 1.5 & \multirow{3}{*}{428} & 603 & 0.8 & $0.55 / 0.33$ \\
\hline GP3-2 & & 2 & & 857 & 0.7 & $0.25 / 0.11$ \\
\hline GP3-2.5 & & 2.5 & & 647 & 0.9 & $0.39 / 0.17$ \\
\hline
\end{tabular}

$529 \quad \overline{\mathrm{CFRP}}=$ carbon fiber reinforced polymer

530 GFRP $=$ glass fiber reinforced polymer

531 (...) indicate the number of drop if the specimen did not fail at the previous drop

532 - not applicable 
$533 \quad$ \# data lost

534 * if SG 1 failed, the strain of FRP was reported the values of SG2

$535{ }^{* *}$ the first number is the maximum strain while the second number is the residual strain 


\begin{tabular}{lccccc}
\hline \multirow{2}{*}{ Specimen } & Max FRP & FRP efficiency & \multicolumn{3}{c}{ Strain rate (1/s) } \\
\cline { 4 - 6 } & strain (\%) & factor & SG 1 & SG 2 & SG 3 \\
\hline CF1_2.5(2) & 0.37 & 0.21 & 15.42 & $\#$ & $\#$ \\
CF1_1.5 & - & $*$ & $\#$ & 7.03 & 10.71 \\
CF2_2.5(2) & - & $*$ & $\#$ & 3.98 & $\#$ \\
CF2_2.5 & 0.24 & 0.14 & 2.76 & 6.49 & 1.38 \\
\hline GF1_2 & 1.30 & 0.66 & 19.12 & 25.00 & 8.00 \\
GF2_2(3) & 0.70 & $*$ & 9.72 & $\#$ & $\#$ \\
GF2_2.5 & 0.70 & $*$ & 13.21 & 7.33 & $\#$ \\
GF2_3 & - & $*$ & $\#$ & 13.68 & 43.33 \\
GF3_2.5 & 0.98 & 0.50 & 5.24 & 5.31 & $\#$ \\
GF3_2.5(2) & 0.27 & $*$ & 3.60 & 8.35 & $\#$ \\
GF3_2.5(3) & 0.26 & $*$ & 2.32 & 5.28 & $\#$ \\
GF3_2.5(4) & 0.38 & $*$ & 3.73 & 5.17 & $\#$ \\
GF3_3 & 1.00 & $*$ & 16.13 & 8.21 & $\#$ \\
GF3_3(2) & - & $*$ & $\#$ & 4.90 & $\#$ \\
GF3_3(3) & - & $*$ & $\#$ & 4.65 & $\#$ \\
GF3_3.5 & 1.03 & 0.52 & 9.90 & 6.98 & $\#$ \\
GF3_3.5(2) & 0.25 & $*$ & 4.03 & 4.24 & $\#$ \\
\hline
\end{tabular}

537 - strain gauges failed

$538 *$ FRP efficiency factor only calculated from strain gauges capturing rupture

$539{ }^{\#}$ not applicable 


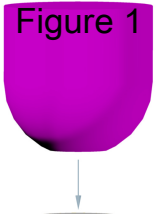

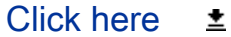
to
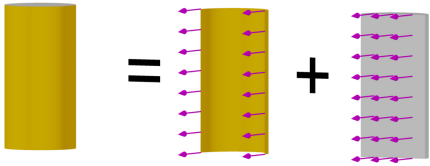
Fig. 2

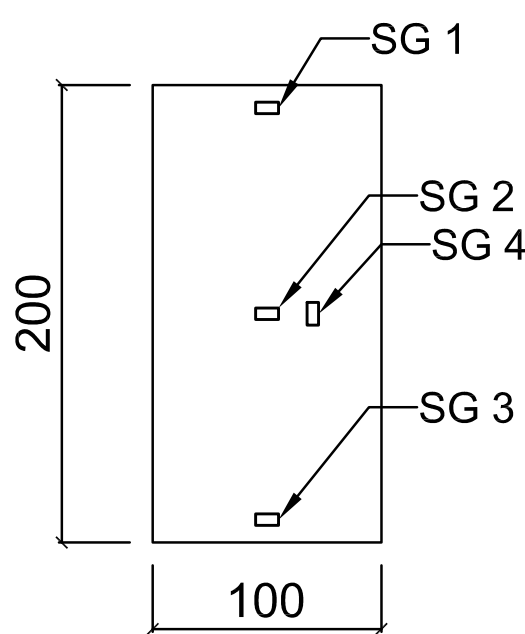

R

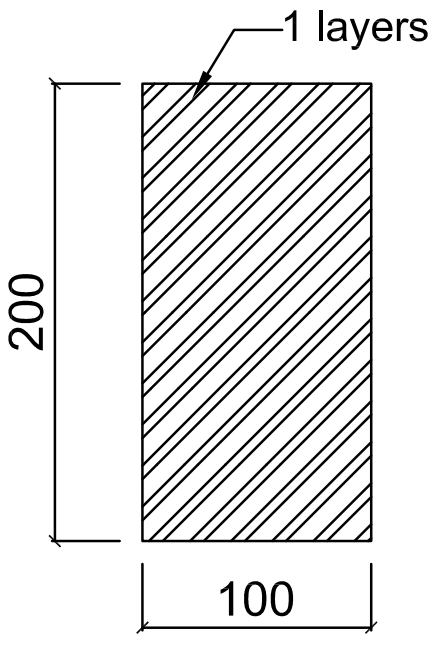

CF1

Sufficient confinement

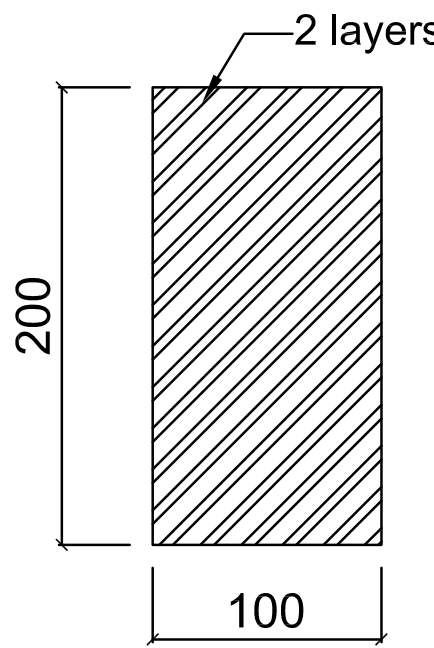

GF2

Sufficient confinement

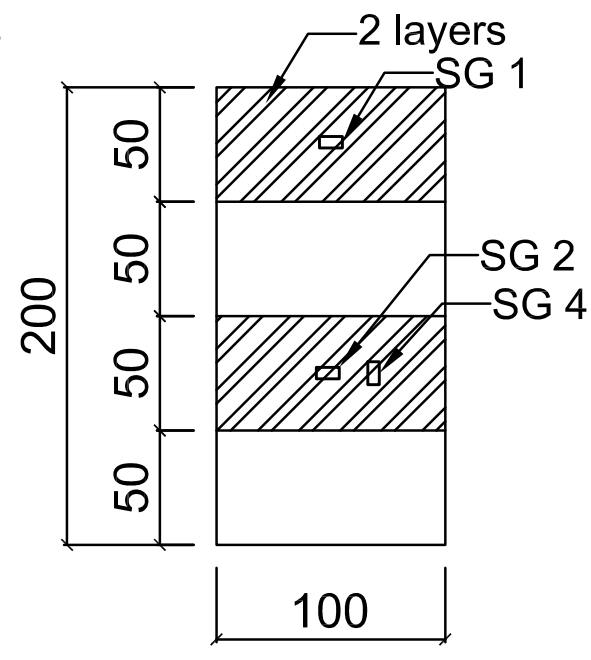

GP2
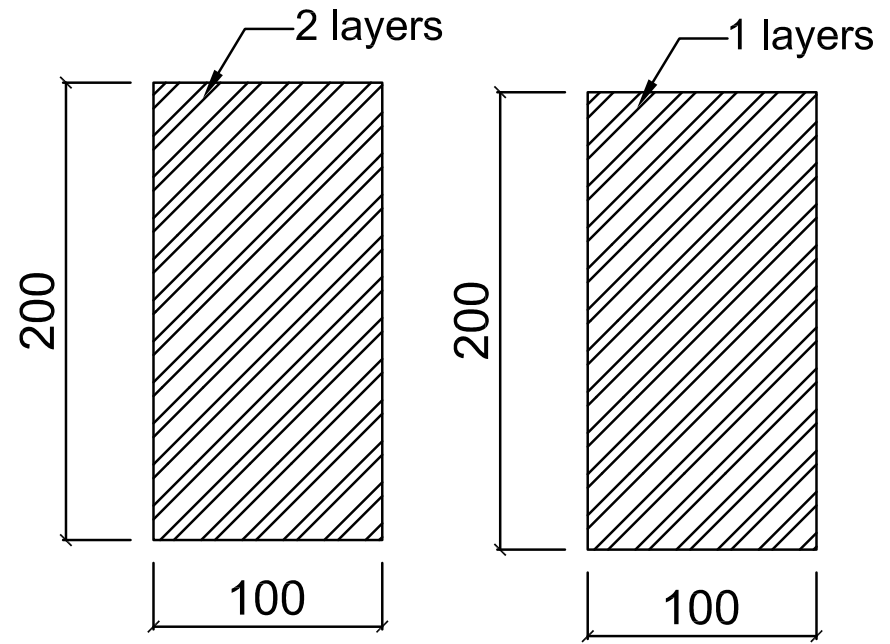

CF2 Heavy confinement

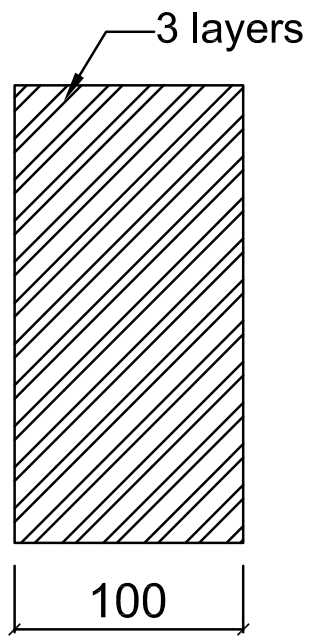

GF3

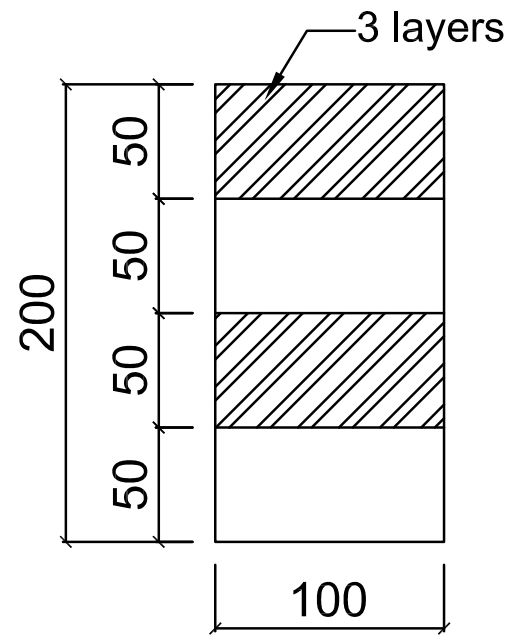

GP3
GF1 Insufficient confinement

Heavy confinement 
Fig. 3

\section{Guiding tube}

Projectile

Specimen

Load cell

8

$+$

Hi 0 
Figure 4

Fig. 4

Click here to download Figure Fig. 4 Sampling rate effect.pdf $\underline{\underline{\underline{*}}}$
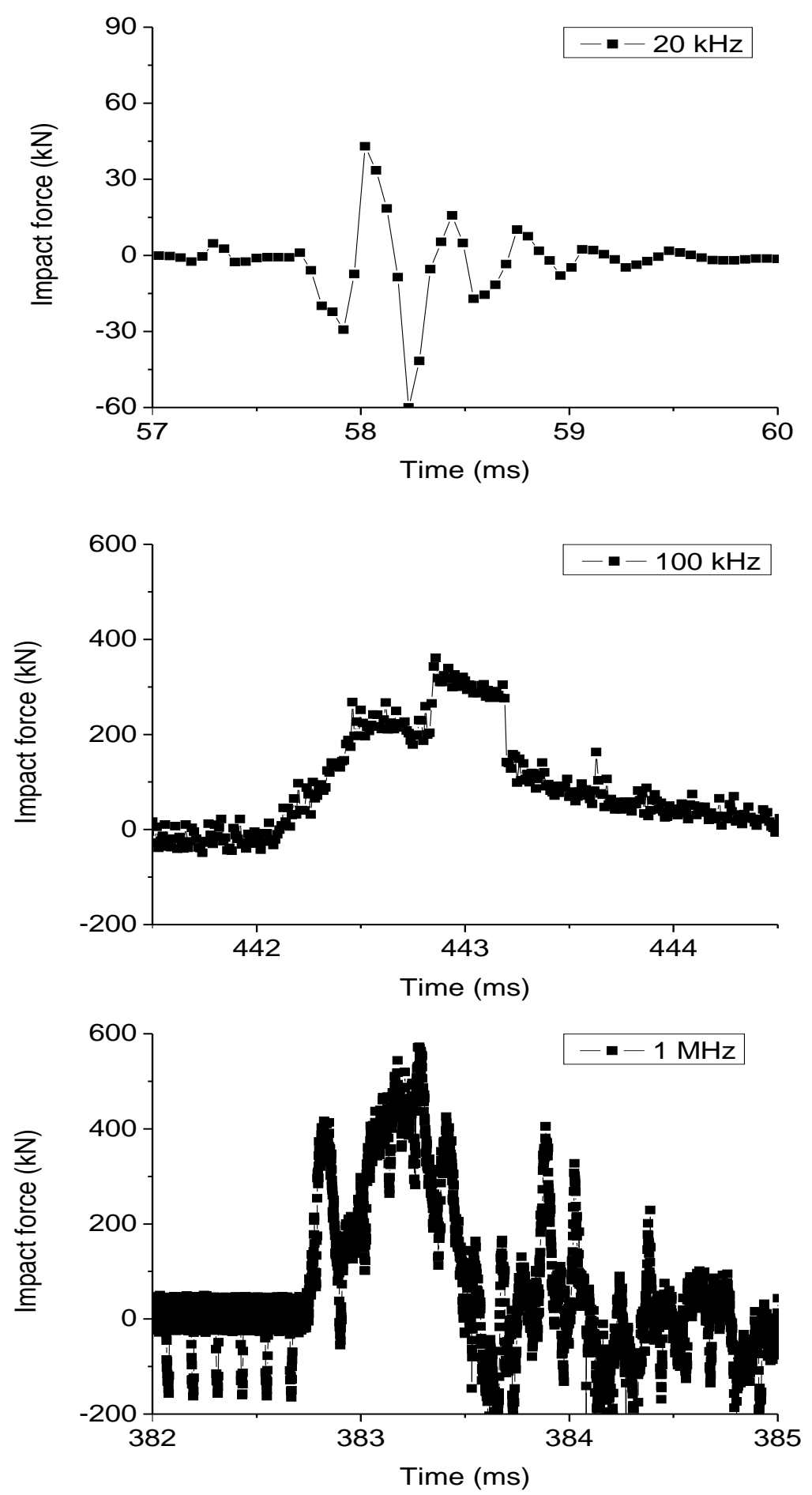
Fig. 5

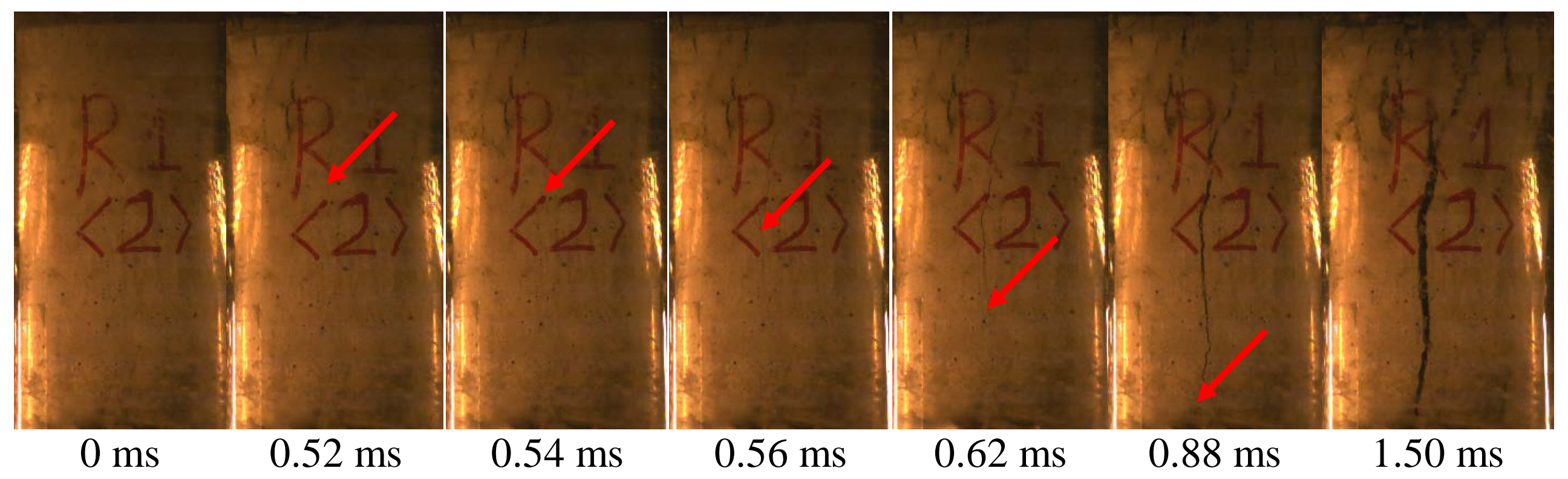


Fig. 6

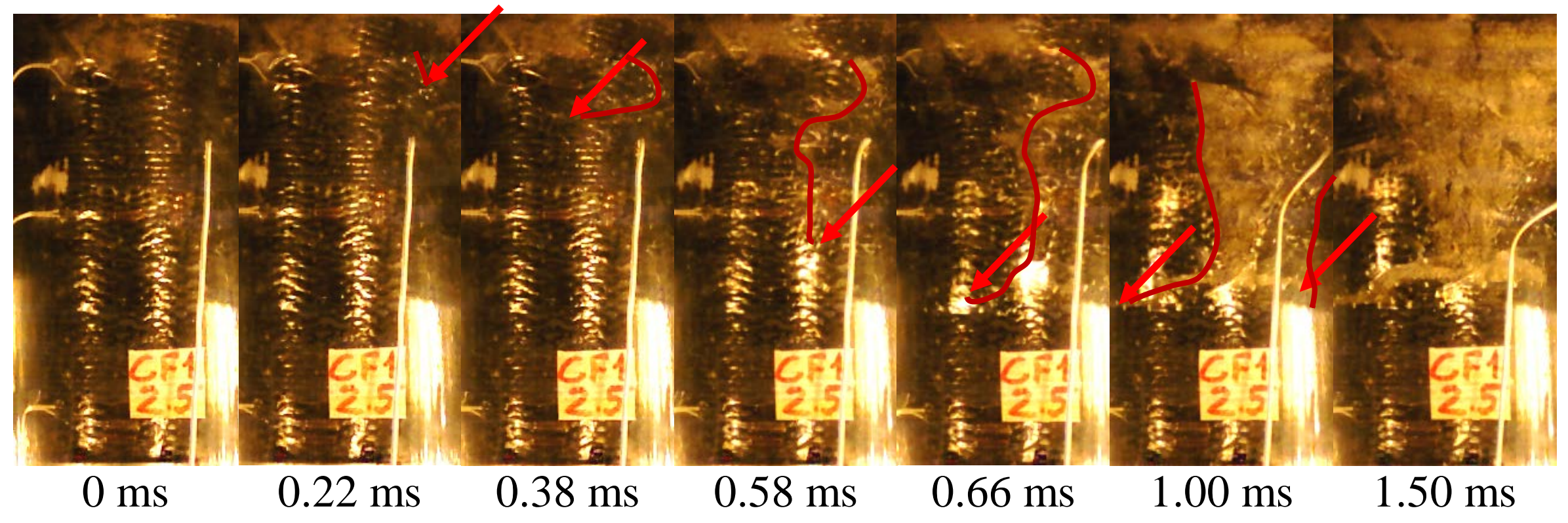


Fig. 7

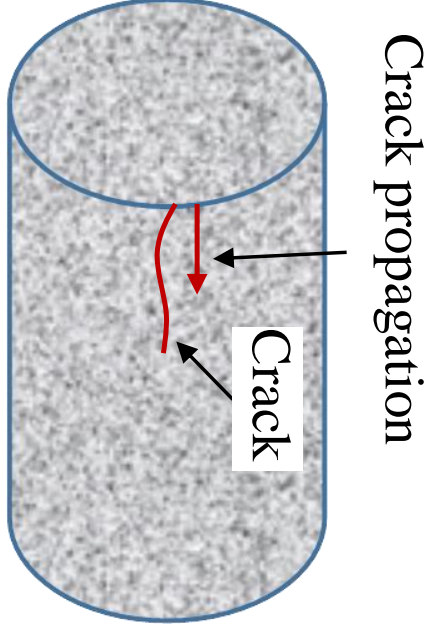

Failure propagation initiates at the impact end

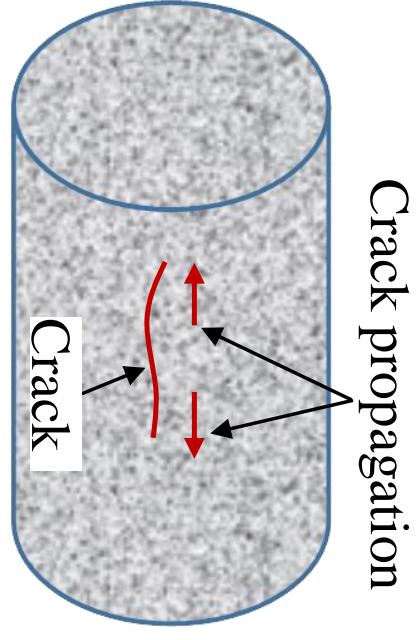

Failure propagation initiates at the midheight 


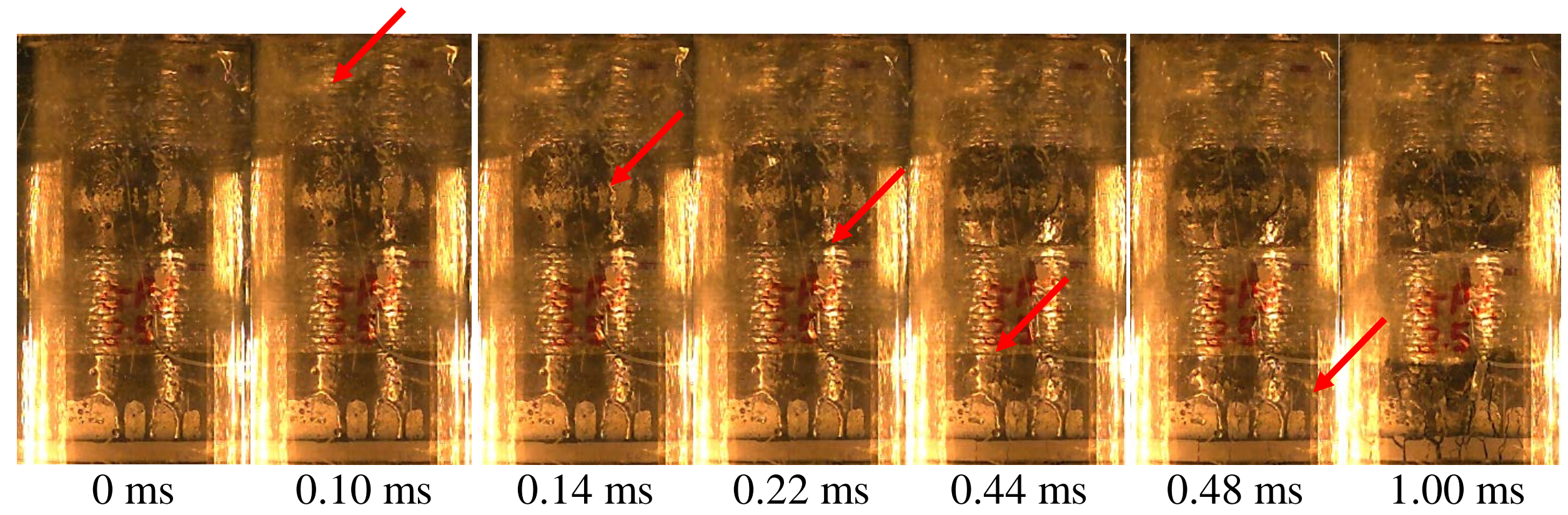




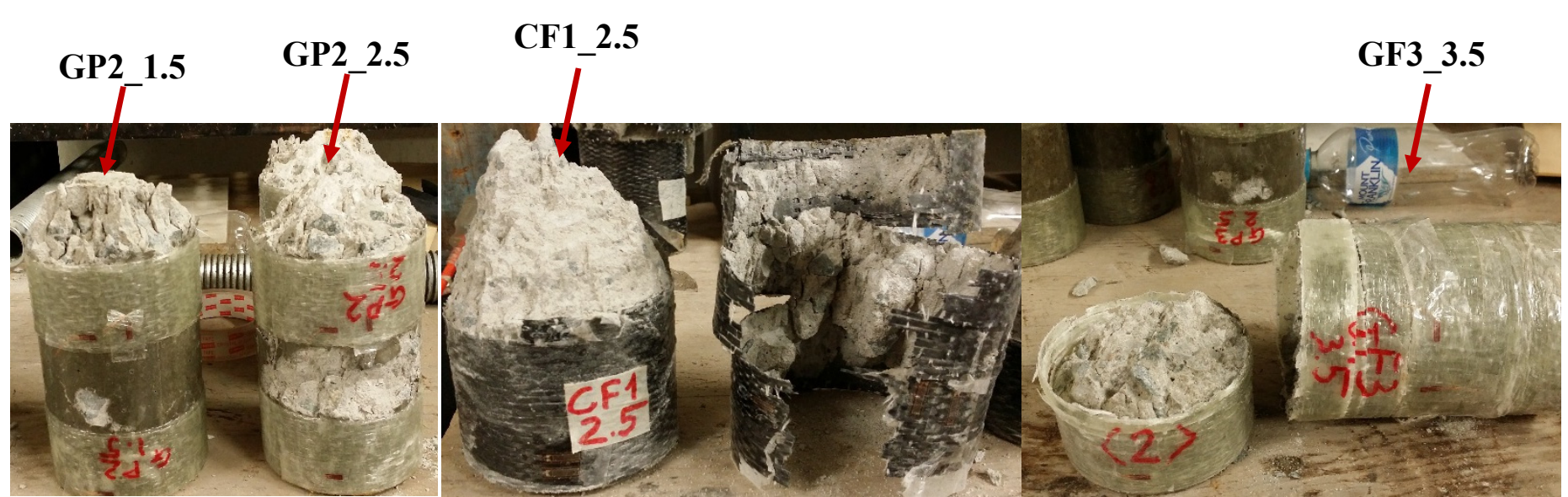

a. Partially confined concrete (Upside down) b. Inclined failure surface c. Complete failure of concrete core 


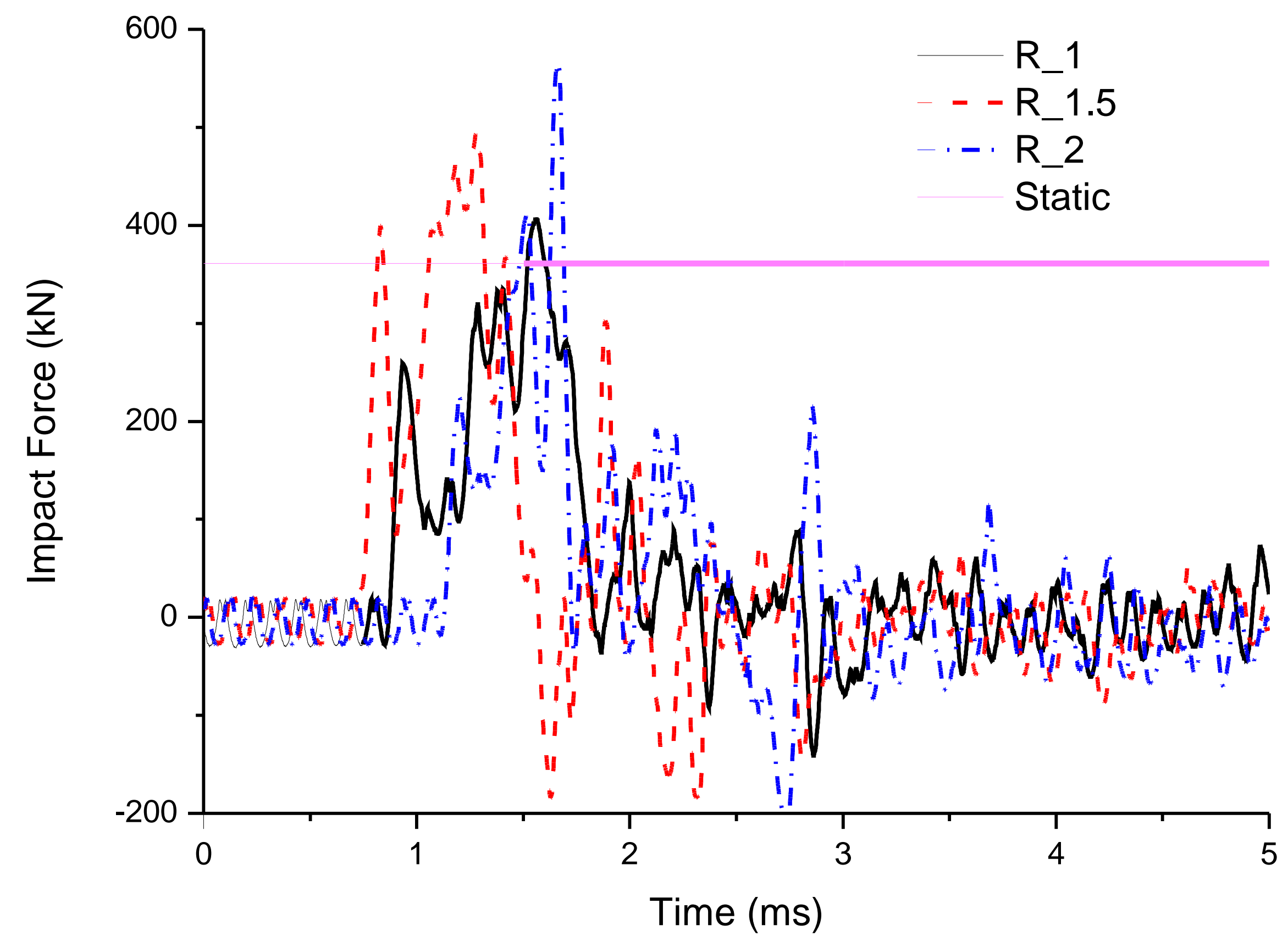




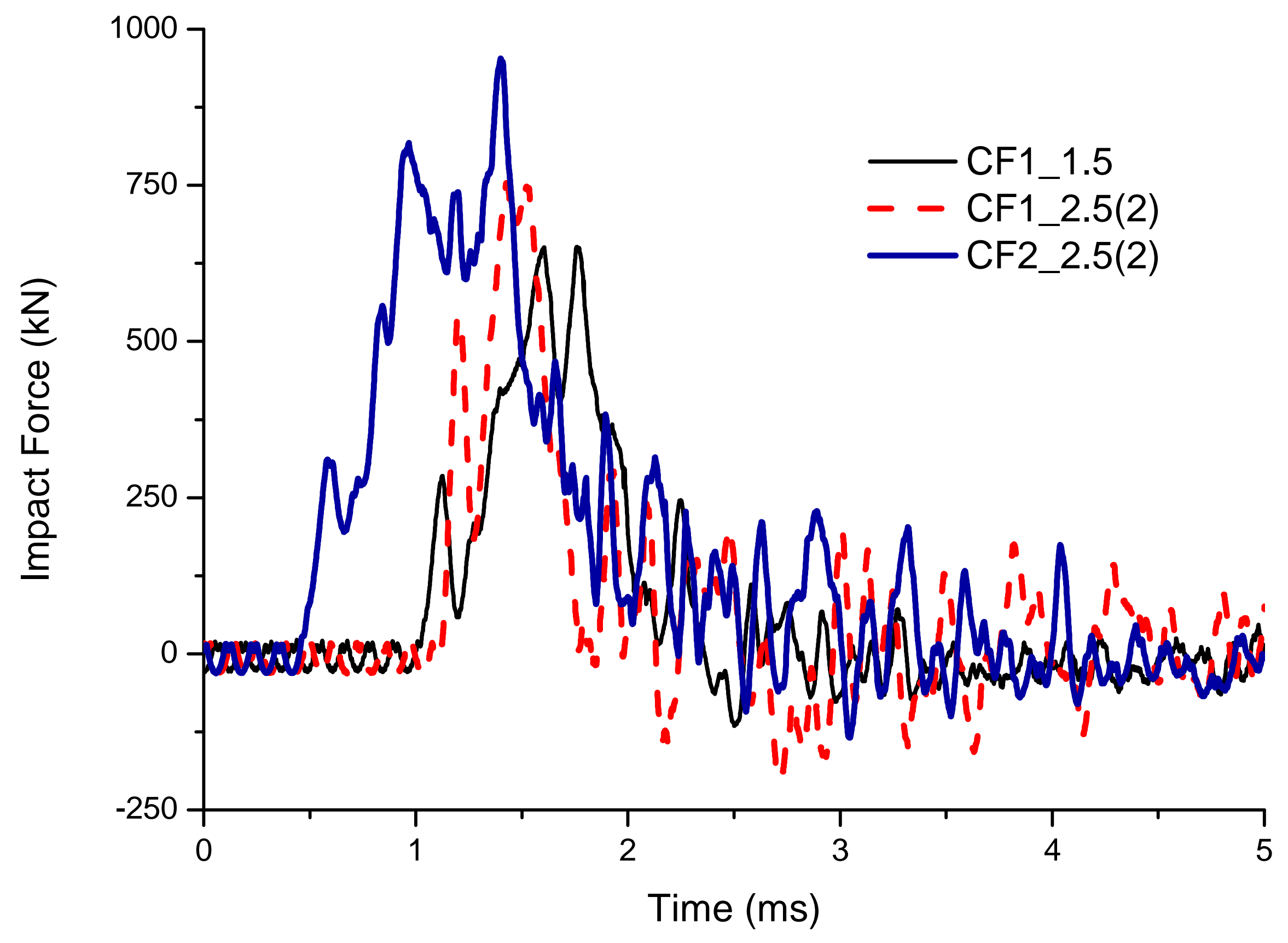




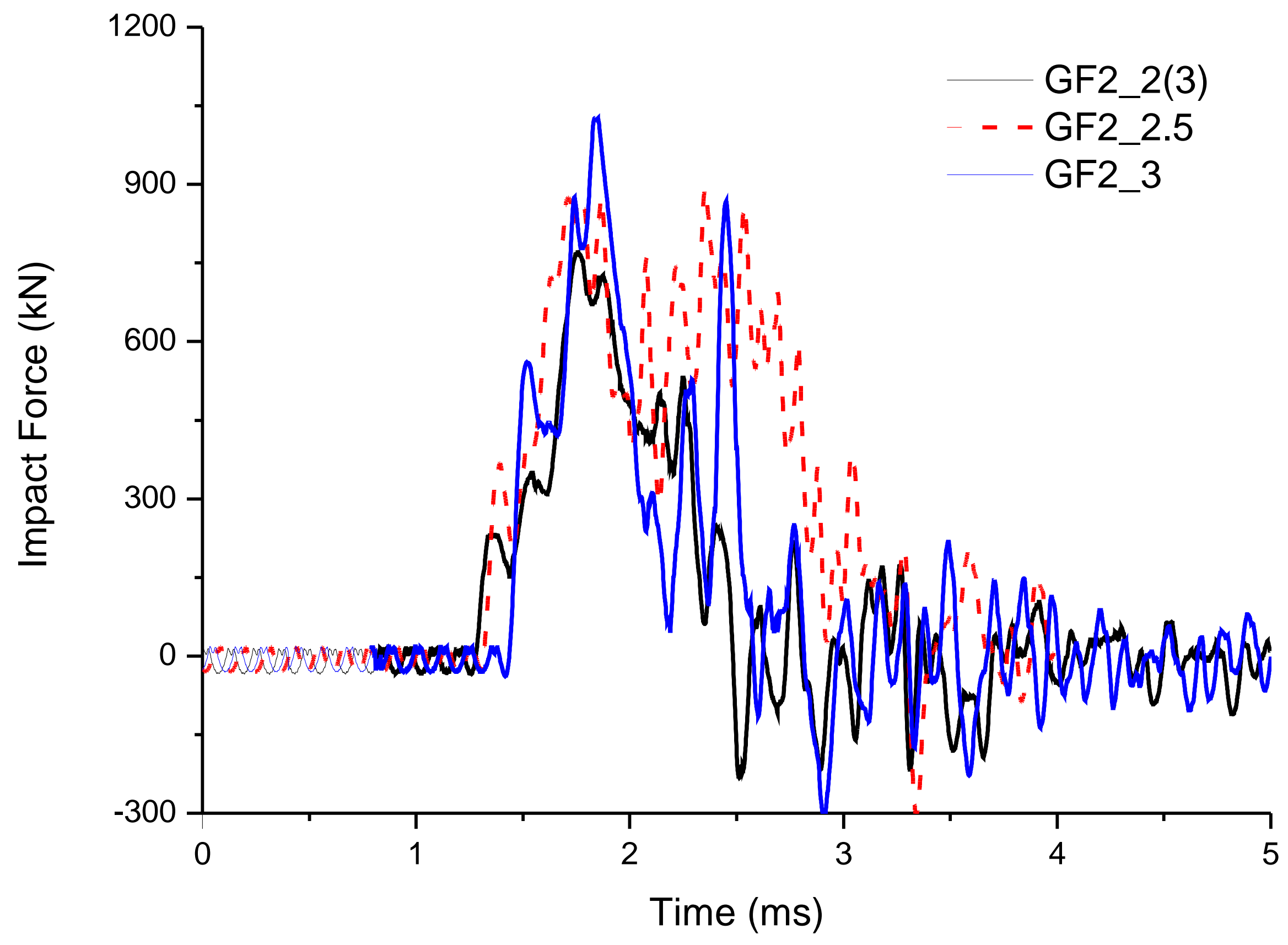


Fig. 13
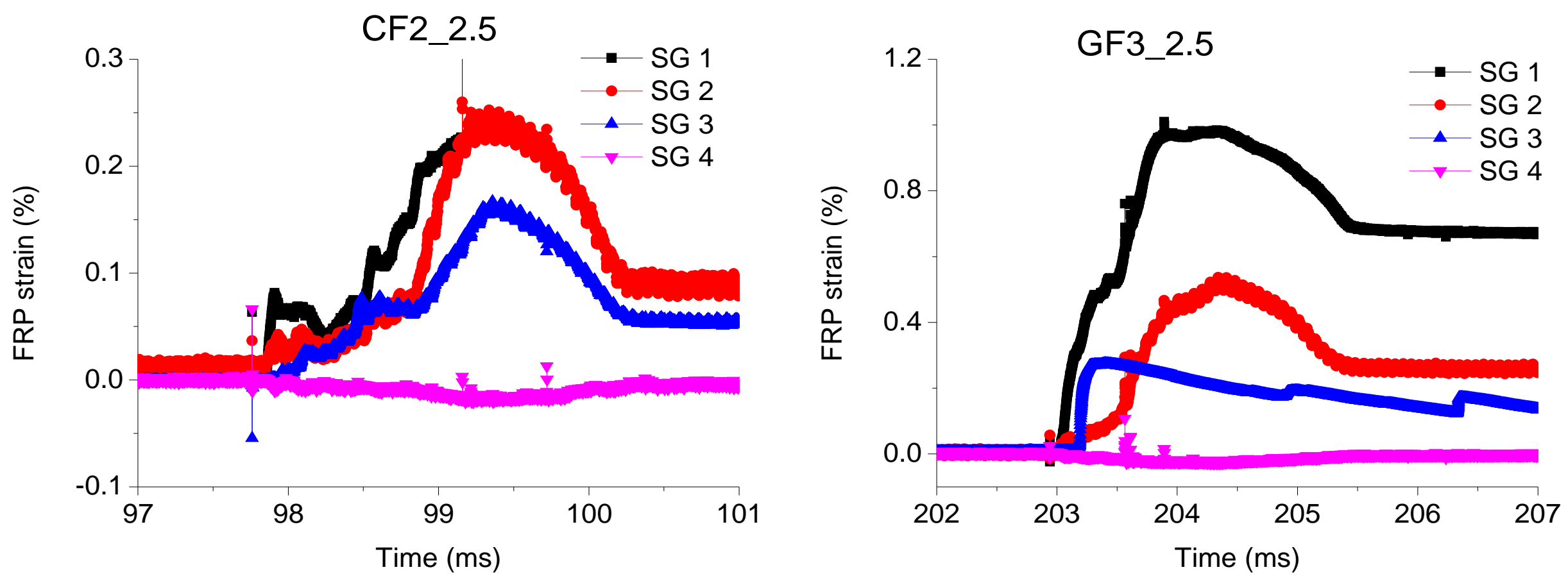
Fig. 14
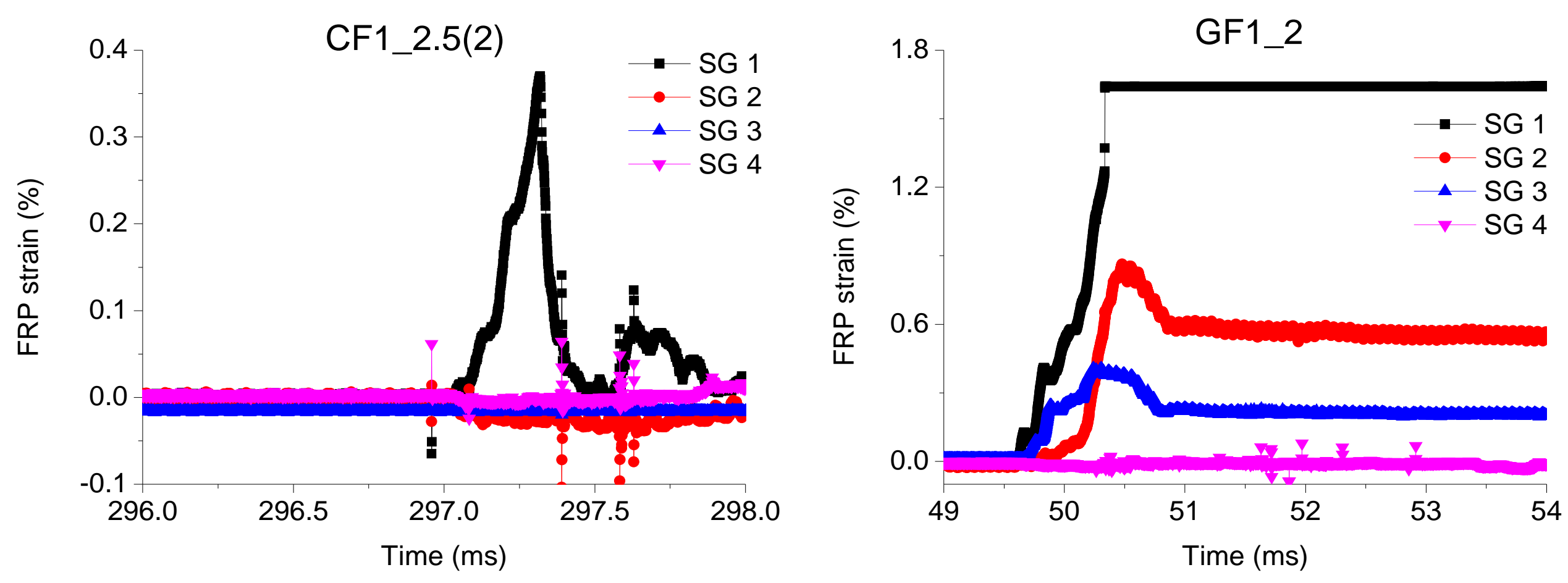
Fig. 15 effects $(k e=0.55)$.pdf

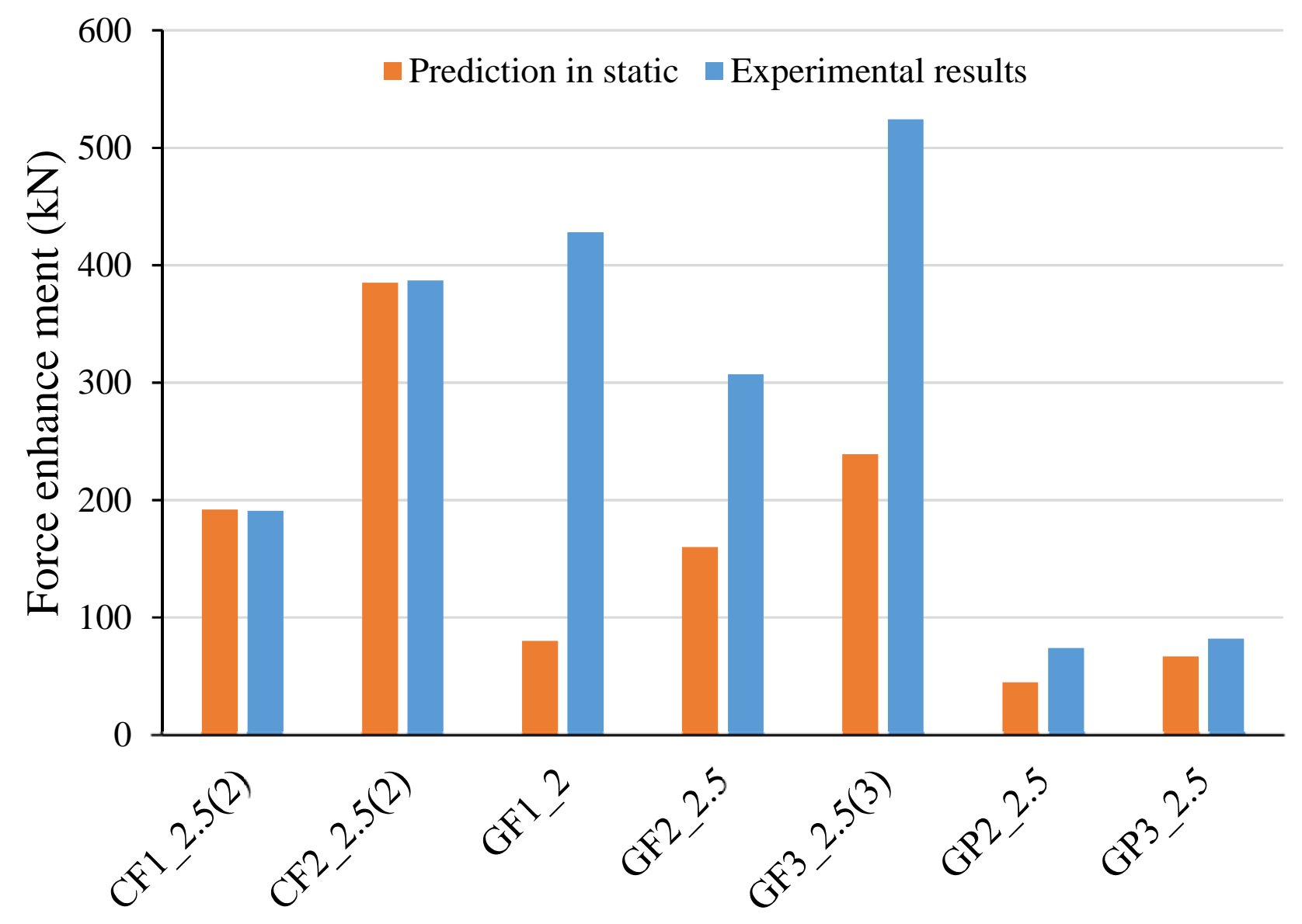


Fig. 16 effects ( $k$ e $=0.18$ and 0.56 for CFRP and GFRP,

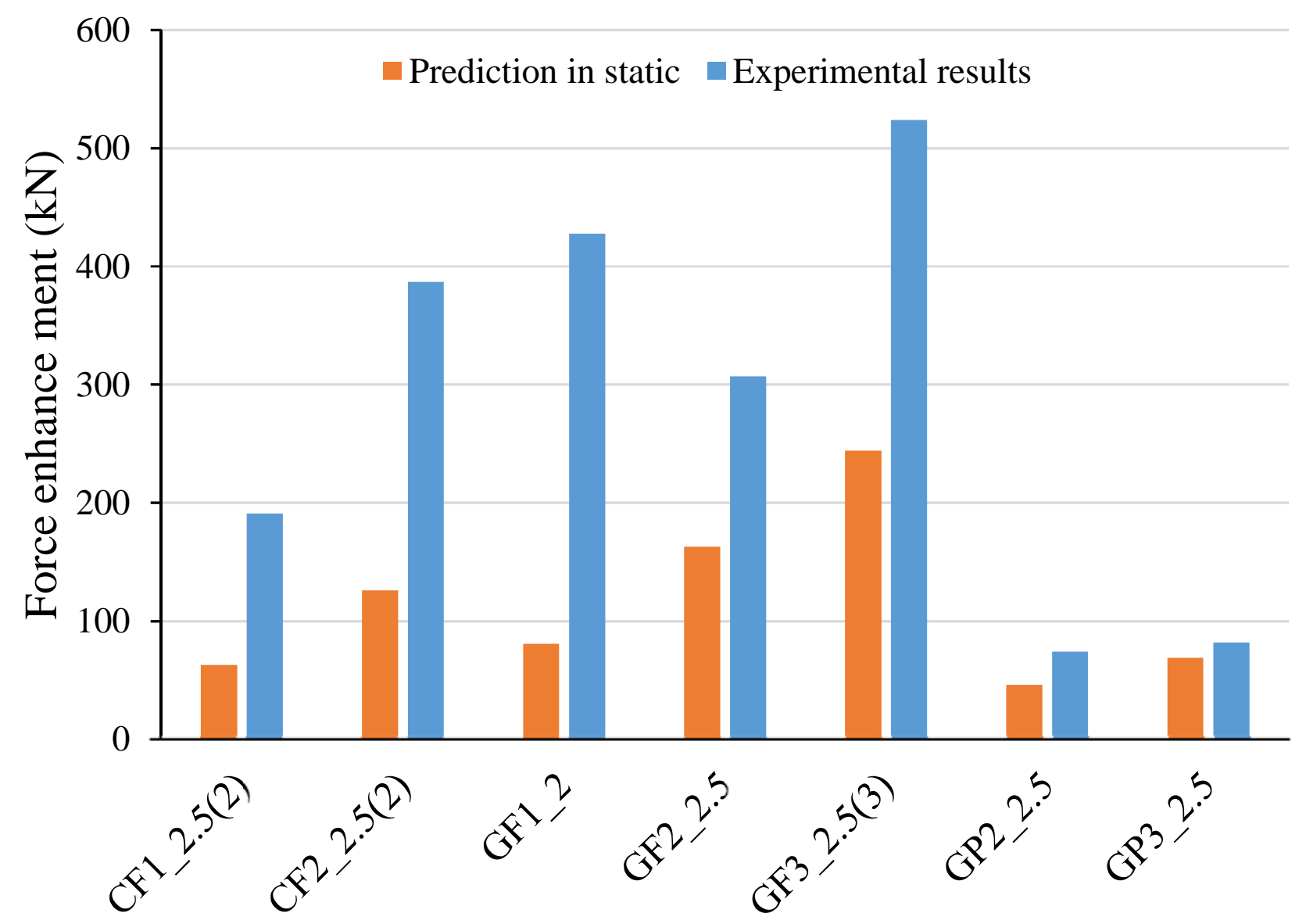


Fig. 17

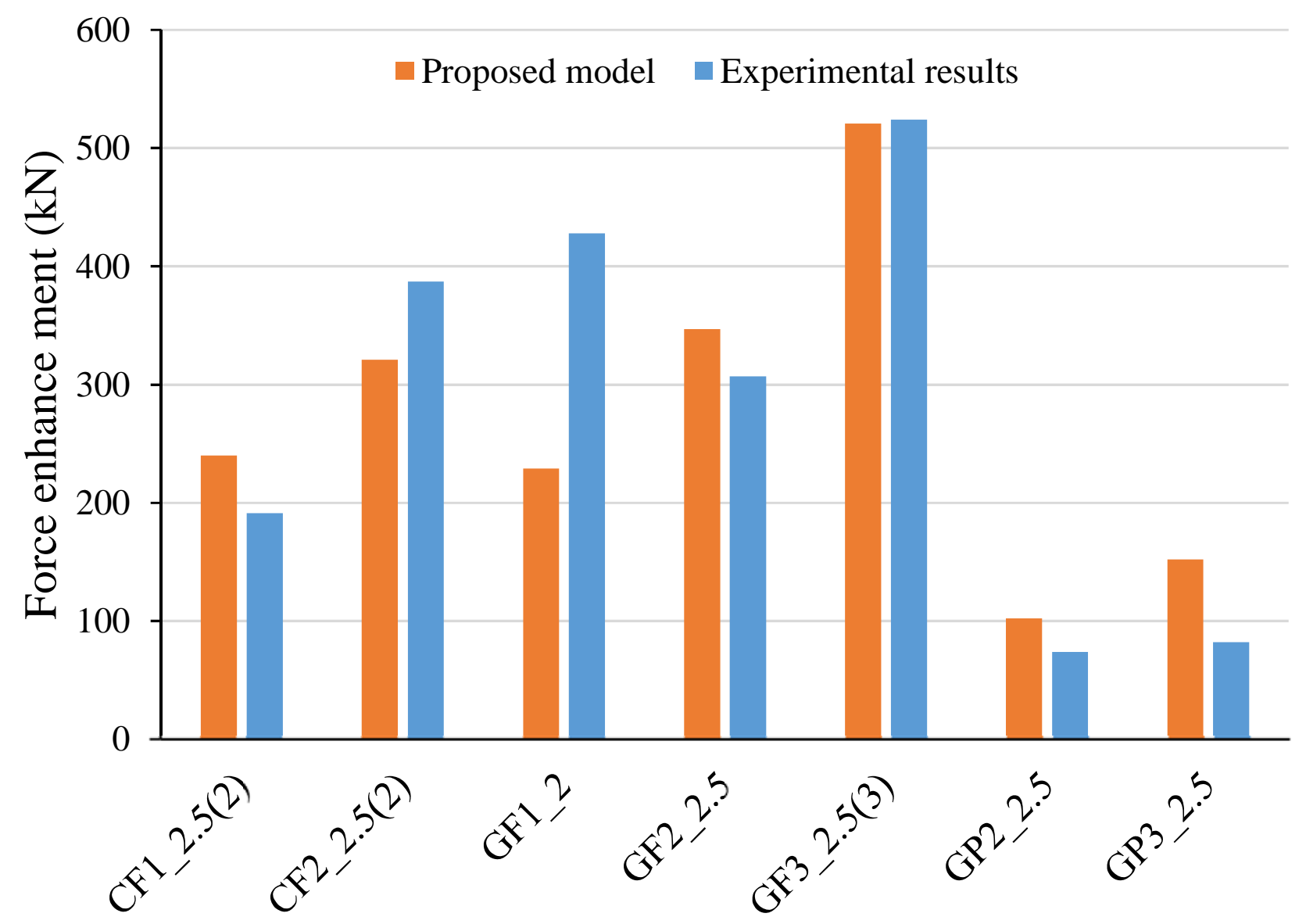




\section{ASCE Authorship, Originality, and Copyright Transfer Agreement}

Publication Title: Journal of Composites for Construction

Manuscript Title: Axial Impact Resistance of FRP-Confined Concrete

Author(s) - Names, postal addresses, and e-mail addresses of all authors

Thong Pham, Research Fellow. Center for Infrastructural Monitoring and Protection. School of Civil and Mechanical Engineering, Curtin University, Kent Street, Bentley, WA 6102, Australia (corresponding author). Emaili: thong.pham (1)curtin. edu.au

Hong Hao, John Curtin Distinguished Professor, Center for Infrastructural Monitoring and Protection, School of Civil and Mechanical Engineering, Curtin University, Kent Street, Bentley, WA 6102, Australia. Email: hong.haoegruntin. edu.au

\section{Authorship Responsibility}

To protect the integrity of authorship, only people who have significantly contributed to the research or project and manuscript preparation shall be listed as coauthors. The corresponding author attests to the fact that anyone named as a coauthor has seen the final version of the manuscript and has agreed to its submission for publication. Deceased persons who meet the criteria for coauthorship shall be included, with a footnote reporting date of death. No fictitious name shall be given as an author or coauthor. An author who submits a manuscript for publication accepts responsibility for having properly included all, and only, qualified coauthors.

I, the corresponding author, confirm that the authors listed on the manuscript are aware of their authorship status and qualify to be authors on the manuscript according to the guidelines above.

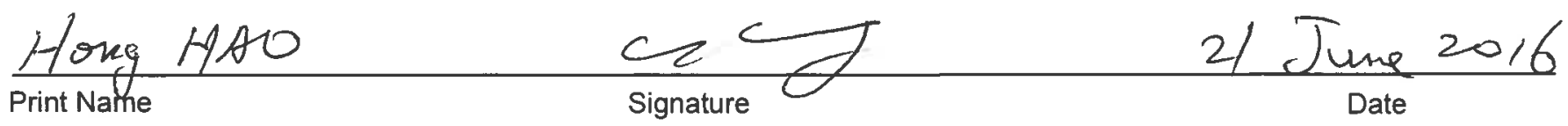

\section{Originality of Content}

ASCE respects the copyright ownership of other publishers. ASCE requires authors to obtain permission from the copyright holder to reproduce any material that (1) they did not create themselves and/or (2) has been previously published, to include the authors' own work for which copyright was transferred to an entity other than ASCE. Each author has a responsibility to identify materials that require permission by including a citation in the figure or table caption or in extracted text. Materials re-used from an open access repository or in the public domain must still include a citation and URL, if applicable. At the time of submission, authors must provide verification that the copyright owner will permit re-use by a commercial publisher in print and electronic forms with worldwide distribution. For Conference Proceeding manuscripts submitted through the ASCE online submission system, authors are asked to verify that they have permission to re-use content where applicable. Written permissions are not required at submission but must be provided to ASCE if requested. Regardless of acceptance, no manuscript or part of a manuscript will be published by ASCE without proper verification of all necessary permissions to re-use. ASCE accepts no responsibility for verifying permissions provided by the author. Any breach of copyright will result in retraction of the published manuscript.

I, the corresponding author, confirm that all of the content, figures (drawings, charts, photographs, etc.), and tables in the submitted work are either original work created by the authors listed on the manuscript or work for which permission to reuse has been obtained from the creator. For any figures, tables, or text blocks exceeding 100 words from a journal article or 500 words from a book, written permission from the copyright holder has been obtained and supplied with the submission.

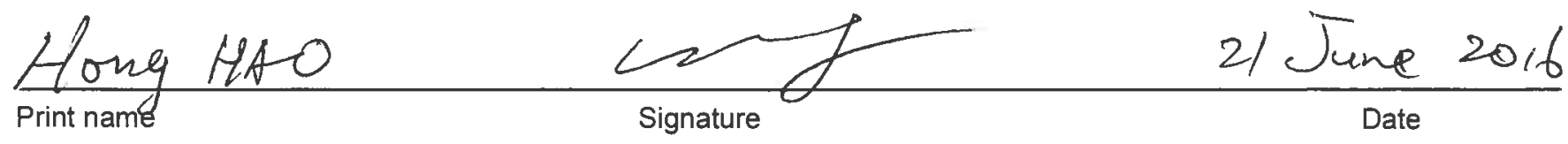

\section{Copyright Transfer}

ASCE requires that authors or their agents assign copyright to ASCE for all original content published by ASCE. The author(s) warrant(s) that the above-cited manuscript is the original work of the author(s) and has never been published in its present form. 
The undersigned, with the consent of all authors, hereby transfers, to the extent that there is copyright to be transferred, the exclusive copyright interest in the above-cited manuscript (subsequently called the "work") in this and all subsequent editions of the work (to include closures and errata), and in derivatives, translations, or ancillaries, in English and in foreign translations, in all formats and media of expression now known or later developed, including electronic, to the American Society of Civil Engineers subject to the following:

- The undersigned author and all coauthors retain the right to revise, adapt, prepare derivative works, present orally, or distribute the work, provided that all such use is for the personal noncommercial benefit of the author(s) and is consistent with any prior contractual agreement between the undersigned and/or coauthors and their employer(s).

- No proprietary right other than copyright is claimed by ASCE.

- If the manuscript is not accepted for publication by ASCE or is withdrawn by the author prior to publication (online or in print), or if the author opts for open-access publishing during production (journals only), this transfer will be null and void.

- Authors may post a PDF of the ASCE-published version of their work on their employers' Intranet with password protection. The following statement must appear with the work: "This material may be downloaded for personal use only. Any other use requires prior permission of the American Society of Civil Engineers."

- Authors may post the final draft of their work on open, unrestricted Internet sites or deposit it in an institutional repository when the draft contains a link to the published version at www. ascelibrary.org. "Final draft" means the version submitted to ASCE after peer review and prior to copyediting or other ASCE production activities; it does not include the copyedited version, the page proof, a PDF, or full-text HTML of the published version.

Exceptions to the Copyright Transfer policy exist in the following circumstances. Check the appropriate box below to indicate whether you are claiming an exception:

U.S. GOVERNMENT EMPLOYEES: Work prepared by U.S. Government employees in their official capacities is not subject to copyright in the United States. Such authors must place their work in the public domain, meaning that it can be freely copied, republished, or redistributed. In order for the work to be placed in the public domain, ALL AUTHORS must be official U.S. Government employees. If at least one author is not a U.S. Government employee, copyright must be transferred to ASCE by that author.

CROWN GOVERNMENT COPYRIGHT: Whereby a work is prepared by officers of the Crown Government in their official capacities, the Crown Government reserves its own copyright under national law. If ALL AUTHORS on the manuscript are Crown Government employees, copyright cannot be transferred to ASCE; however, ASCE is given the following nonexclusive rights: (1) to use, print, and/or publish in any language and any format, print and electronic, the above-mentioned work or any part thereof, provided that the name of the author and the Crown Government affiliation is clearly indicated; (2) to grant the same rights to others to print or publish the work; and (3) to collect royalty fees. ALL AUTHORS must be official Crown Government employees in order to claim this exemption in its entirety. If at least one author is not a Crown Government employee, copyright must be transferred to ASCE by that author

WORK-FOR-HIRE: Privately employed authors who have prepared works in their official capacity as employees must also transfer copyright to ASCE; however, their employer retains the rights to revise, adapt, prepare derivative works, publish, reprint, reproduce, and distribute the work provided that such use is for the promotion of its business enterprise and does not imply the endorsement of ASCE. In this instance, an authorized agent from the authors' employer must sign the form below.

U.S. GOVERNMENT CONTRACTORS: Work prepared by authors under a contract for the U.S. Government (e.g., U.S. Government labs) may or may not be subject to copyright transfer. Authors must refer to their contractor agreement. For works that qualify as U.S. Government works by a contractor, ASCE acknowledges that the U.S. Government retains a nonexclusive, paid-up, irrevocable, worldwide license to publish or reproduce this work for U.S. Government purposes only. This policy DOES NOT apply to work created with U.S. Government grants.

I, the corresponding author, acting with consent of all authors listed on the manuscript, hereby transfer copyright or claim exemption to transfer copyright of the work as indicated above to the American Society of Civil Engineers.

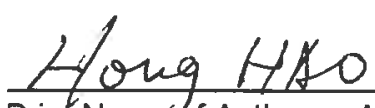

Print Namefof Author or Agent

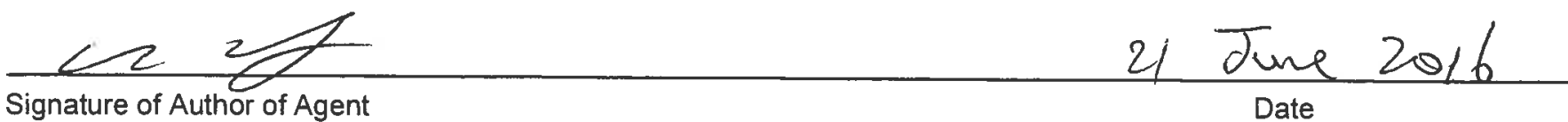

Signature of Author of Agent Date

More information regarding the policies of ASCE can be found at http://www.asce.org/authorsandeditors 


\section{ADDRESSING REVIEWERS' COMMENTS}

2 Ref.: Ms. No. CCENG-1833

3 Impact Resistance of FRP-Confined Concrete

4 Thong Minh Pham, PhD; Hong Hao, PhD

5

The authors would like to thank the editors/reviewers for their time and effort spent into reviewing the manuscript. Their comments and suggestions have contributed to the improvement of the revised manuscript. All recommendations and comments have been carefully taken into consideration. Please refer to answers below for detailed modifications.

\section{Editor's comments:}

-One major issue raised by multiple reviewers is the apparently static nature of the input properties when the problem at hand is dynamic. This needs to be addressed in the paper by using dynamic properties or else justifying the use of static props. based on the literature or the author's data.

Answer: The discussion and justification of using static material properties have been added to the manuscript. Please refer to Lines 114-129 and 402-412.

-Improved explanation of novelty of work, in light of the literature, is needed in the abstr., intro., and conclusions.

Answer: Explanations have been added to the manuscript to highlight the research significance and findings of the work. Please refer to Lines 15-16, 71-74 and 414-434.

-Improved discussion of the results is needed. Possible comparison with results in literature.

Answer: The discussion section of the manuscript has been revised, please refer to Lines 399-412.

It has been mentioned in the manuscript the experimental results regarding this topic is very limited in the literature. Effort has been paid to validate the proposal model with three previous studies 
mentioned in this paper. However, a comparison could not be made due to the lack of sufficient information, for example, the dynamic concrete strength and strain rate were not provided in the previous publications (Uddin et al. 2008; Xiao and Shen 2012). Without these data, comparisons with the presented results in the current manuscript are not possible. The experimental results from the studies (Shan et al. 2007; Xiao and Shen 2012) were about FRP confined concrete filled steel tubular columns at which the proposed model is not applicable.

-L454. Check volume "O" in Z Xu paper.

Answer: The reference has been revised. Please refer to Line 513.

-L418. Check issue "0" in Y Hao paper.

Answer: The reference has been revised. Please refer to Line 462.

\section{Reviewers' comments:}

\section{Reviewer \#1:}

The authors present an interesting paper on dynamic loading of concrete confined by FRP material. This experimental study is original and only very few studies have been done on this topic. The paper is well written even if the last part can be withdraw to improove quality of the paper.

- page 4 line 77 : confinement pressure depends linearly on FRP thickness, the obtained results seems not increase linearly, authors should more describe this phenomenon

Answer: The reviewer is correct that the confining pressure depends linearly on FRP thickness. The results also show that the strength enhancement increased approximately in a linear relationship with the FRP thickness (see Fig. 17). It is noted that a comparison of the axial impact resistance only can be made if two specimens have the same impact velocity. Taking the above condition into account, Figure 17 shows the force enhancement of Specimens CF1_2.5(2) and CF2_2.5(2) were $191 \mathrm{kN}$ and $387 \mathrm{kN}$, respectively. A similar observation can be also found from Specimens GF2_2.5 and GF3_2.5(3). These values showed an approximately linear relationship. 
- page 7 : mechanical properties of FRP are given based on static properties, what about dynamic properties?

Answer: At the highest strain rate in this study, the dynamic tensile strength of FRP increases about 2.8\%. Therefore the enhancement on the dynamic tensile strength can be ignored in the low impact velocity tests in this study. Discussion and justification of ignoring the strain rate effect on the dynamic properties of FRP have been added to the manuscript. Please refer to Lines 113-126.

- page 8 : cumulative impact may affect results, reviewer understand the purpose on the test principle to limit the samples number, but this could be discuss

Answer: Three impact tests were conducted on three identical unconfined concrete cylinders. No specimen was repeatedly impacted in the test for determination of the sampling rate. Please refer to Lines 178-192 Page 8. The reviewer is correct that the cumulative impact may affect results. This study discussed this effect on the failure mode, please refer to Lines 215-243.

- page 16 line 348 : proposed model seems to be hazardous, why authors consider the same value for tensile strength of CFRP on dynamic and static loading, $k$ factor could be affected by this,

Answer: The consideration of the dynamic tensile strength of FRP and dynamic compressive strength of concrete has been added to the manuscript. Please refer to Lines 114-129 and 402-412.

- page 16 : authors mention dynamic properties of concrete obtained by a model, this should be detailed and discuss, how this can modify the obtained results

Answer: More information about determining the compressive strength of unconfined concrete under high load rate has been added. Please refer to Lines 402-412.

- figure 13 : load versus time to show two or three pick load, how can this be explained?

Answer: Figure 13 described the time history of FRP strain. The load histories are presented in Figures 10-12. The zigzag curves presented in this study may be resulted from the interference of the stress waves. The projectile impacts the specimen and generates stress waves propagating from 
the top to the bottom of the specimen. These stress waves propagate in the specimens back and forth many times. The load cell actually measured the wave interference of these waves with the shape of a zigzag curve. Similar zigzag curves were also observed in many previous studies e.g., (Xiao and Shen 2012; Xu et al. 2012).

- based on the limited numbers of results, model should be carefully described with a lot of caution

Answer: The authors thank the reviewer for the useful comment. Some discussions were added to the manuscript to state the limitations of the model owing to the limited number of results, please refer to Lines 392-397.

- table $1:$ why the word beam appear in the table?

Answer: The typo has been fixed. Please refer to Table 1.

\section{Reviewer \#2:}

Summary

The effect of impact using drop weight apparatus on FRP-confined concrete cylinders was investigated experimentally and accompanied by an analytical model. The FRP rupture strain was substantially lower when performing dynamic test as oppose to static test. Variables considered were FRP material types and number of FRP layers.

\section{General Comments}

The present study seems to offer minimal new findings. Most of authors' observations have been mentioned in similar studies by other researchers. The analytical part is very short and mostly adopts few existing equations in the literature with limited experimental data to back up. One way to address this deficiency is by comparing the analytical model to other researchers' experimental data.

Answer: This is a complex comment. The authors would like to answer in three main areas: the findings of the study, the discussion, and the validation of the proposed model.

This study focuses on the axial impact resistance of FRP-confined concrete while other studies investigating the impact behavior of concrete filled steel tubular concrete strengthened with FRP 
(Shan et al. 2007; Xiao and Shen 2012). The specimens of these two papers had two jackets including steel tube and FRP. It is well known that the structural behavior of FRP-confined concrete and concrete filled steel tube is different. In addition, the experimental results of the present study show that GFRP (high rupture strain) exhibited better axial impact resistance than that of CFRP (higher strength but lower rupture strain), which has not been reported in the literature. As a result, GFRP is recommended for strengthening structures against impact loads. Explanation to the difference in failure modes, which were observed in previous studies by different researchers, is presented in the current manuscript (please refer to Lines 218-243). Actual rupture strain of FRP under impact loads was reported and discussed for use in predicting the impact resistance of FRP-confined concrete. In addition, this study investigated the effect of the sampling rate on the results and proposed an appropriate range of $\sim 1 \mathrm{MHz}$ to obtain reliable results for similar impact tests.

The axial impact resistance of FRP-confined concrete was experimentally examined so that the manuscript focused on analyzing and discussing the experimental results. The analytical part intends to verify the experimental tests and also to suggest a new model for predicting the axial impact resistance of FRP-confined concrete. More study is needed to provide better understanding of this complicated mechanism.

Effort has been paid to validate the proposed model with three previous studies mentioned in this paper. However, a comparison could not be made due to the lack of sufficient information, for example, in the previous studies (Uddin et al. 2008; Xiao and Shen 2012) the authors did not provide the experimental value of the dynamic concrete strength and strain rate. Without the strain rate, the dynamic concrete strength could not be estimated as presented in the current manuscript. The experimental results from the other two studies (Shan et al. 2007; Xiao and Shen 2012) were 
about FRP confined concrete filled steel tubular columns, which are not the same to the FRP confined concrete columns.

\section{Specific Comments}

Fig. 1 should be modified for clarification.

Answer: Figure 1 has been revised. Please refer to the Figure 1.

In Fig. 8 cracks are not clear in the in the current illustration. The crack patterns can be drawn on the specimens for better clarity.

Answer: Photos of crack patterns and propagation were showed in Figures 5-7. These figures were images from high speed camera so that the quality has some limitation. To provide clearer crack illustration, the authors describe the crack propagation in Figure 8.

In Fig. 15, it seems that static prediction is almost accurate for CFRP confined concrete and partially confined concrete using GFRP. Also increasing the GFRP from 2 to 3 layers did not enhance the force much. Authors are encouraged to rationalize the results.

Answer: In Figure 15, the static FRP efficiency factor (0.55) was used for the confined concrete. They actually did not reflect the real performance of the specimens under the impact tests in which the CFRP efficiency factor was about 0.17 . However, using the actual rupture strain in the current form of the model suggested by ACI 440.2R-08 (2008) did not yield good predictions. Therefore, the authors recommended using the actual rupture strain with recalibrated model (Equation 4). Please refer to Lines 371-412.

Increasing the GFRP layers in fully confinement specimens enhanced the impact force significantly, for instance, the force enhancement of Specimens GF2_2.5 and GF3_2.5(3) were $307 \mathrm{kN}$ and $524 \mathrm{kN}$ (71\% increase), respectively. Please refer to Figure 15. It is noted that increasing GFRP layers in partially confined concrete did not significantly enhance the impact force because the fiber did not rupture while the specimens failed at the unconfined concrete. 
Page 9, why the crack was initiated at 0.4 ms (line 183) for control specimen versus 0.22 (line 187) for FRP confined cylinder?

Answer: Small cracks were observed at the impact end at a very early stage (0.04 ms) after the projectile in contact with the specimen. This statement was presented in the manuscript, please refer to Lines 203-204.

Page 10, how present study results differ than other studies in the literature? What does present study revealed that are not already reported in the mentioned references cited on line 212?

Answer: This study focuses on the axial impact resistance of FRP-confined concrete while other studies investigating the impact behavior of concrete filled steel tubular concrete strengthened with FRP (Shan et al. 2007; Xiao and Shen 2012). The specimens of these two papers had two jackets including steel tube and FRP. It is well known that the structural behavior of FRP-confined concrete and concrete filled steel tube is different. In addition, the experimental results of this study show that GFRP (high rupture strain) exhibited better axial impact resistance than that of CFRP (higher strength but lower rupture strain). As a result, GFRP is recommended for strengthening structures against impact loads. Explanation to the difference in failure modes, observed in previous studies by different researchers, is presented in the current manuscript (please refer to Lines 218-243). Actual rupture strain of FRP under impact loads was reported and discussed for use in predicting the impact resistance of FRP-confined concrete.

Most conclusive remarks are well known. What makes this investigation new?

Answer: The better performance of GFRP versus CFRP in FRP-confined concrete under impact loads has not been reported yet. The study of FRP confined concrete under impact loads are very limited, and those few reported in the literature observed different failure modes as presented in the introduction (please refer to Lines 21-76). Not like specimens under static loads, the failure of the tested specimens in this study was observed at either the impact end or midheight. An attempt 
to explain these failure modes was presented in the manuscript, please refer to Lines 197-243. Careful consideration of the sampling rate was demonstrated critical as it significantly affects the recorded data. Discussions given in the present paper may help future studies obtain more reliable results. It is worth mentioning that the axial impact tests on confined concrete, especially FRP confined concrete is very limited, as commented by Reviewer 1 . The reviewer also may refer to the above answer for more information about the contribution of this study to the literature.

In several parts of the manuscript including line 252-258 discusses other researchers' findings rather than authors own findings.

Answer: In Lines 252-258 of the previous manuscript and Lines 270-281 of the current manuscript, the authors referred to findings from the previous studies to obtain reliable measurements from the impact tests in this study. There have been several ways to measure the impact force, for example, load cells placed either on the top or bottom of specimens, images analyses, or accelerometer etc. The method of measuring the impact force was not the interest of this study. Previous studies were discussed because it is very important to correctly measure the impact force in the tests.

Discussion on the results is limited.

Answer: Interpreting the experimental results was presented in both the sections of Experimental Result and Discussion. However, more discussion has been added to the manuscript. Please refer to Lines 392-412.

There is not enough data in Table 2 to quantify strain energy efficiency etc. for impact.

Answer: It has been reported in the introduction and also confirmed by Reviewer 1 that experimental results about impact tests are very limited. Compared to other studies in the literature, this study in fact provides a lot more results of the impact tests (Shan et al. 2007; Uddin et al. 2008; 
Xiao and Shen 2012). The current paper also provides more detailed observations and discussions of the test data.

\section{Reviewer \#3:}

The manuscript reports some new testing data on FRP confined concrete cylindrical stub columns subjected to axial impact. The manuscript is well written, however, the following issues should be addressed before final acceptance.

1. The title and in the manuscript, the axial impact should be specified.

Answer: The title of the manuscript has been revised. Please refer to Line 1 for the new title.

2. The authors claim to proposed a confinement model. This should be clarified, as, possibly, stating "the widely used simple Mohr Columb was used to express the confinement effect of FRP confined concrete under axial impact. and the dynamic confinement coefficients were suggested"

Answer: The statement has been considered in the manuscript. Please refer to Lines 392-394.

3. It is not clear how the FRP stress was computed, from the strain instrument of the FRP wrapping surfaces. Since the dynamic loading, the FRP should follow a dynamic stress strain model, and the dynamic modulus should be used. It seems that the equation 1 only considered the rupture strength of FRP. Then, there are two questions should be answered, one, whether the rupture of the FRP wrapping was corresponding to the dynamic ultimate strength; two, since dynamic loading, the rupture strength of the FRP should be counted for dynamic increase, and how much is the dynamic strength of the FRP? Non of these questions were seemed to be addressed.

Answer: The authors thank the reviewer for the useful comment. More information and consideration of the dynamic properties of FRP have been added to the manuscript. Please refer to Lines 114-129.

4. Fig.1, the drop head appears to be a spherical one, and this is not true. Suggest to revise the figure to show the flatness of the contacting surface.

Answer: Figure 1 has been revised to better describe the actual shape of the projectile head. Please refer to Figure 1. 
Editorially, the last reference, should be Xiao Y. and Shen Y.L. 2012 (last names), rather than Yan and Yali.

229 Answer: The reference has been revised. Please refer to Lines 509-510.

Reference

$\mathrm{ACl}$ 440.2R-08 (2008). "Guide for the Design and Construction of Externally Bonded FRP Systems for Strengthening Concrete Structures." 440.2R-08, American Concrete Institute, Farmington Hills, MI.

Shan, J. H., Chen, R., Zhang, W. X., Xiao, Y., and Lu, F. Y. (2007). "Behavior of Concrete Filled Tubes and Confined Concrete Filled Tubes under High Speed Impact." Advances in Structural Engineering, 10(2), 209-218.

Uddin, N., Purdue, J. D., and Vaidya, U. (2008). "Feasibility of thermoplastic composite jackets for bridge impact protection." Journal of Aerospace Engineering, 21(4), 259-265.

Xiao, Y., and Shen, Y. (2012). "Impact Behaviors of CFT and CFRP Confined CFT Stub Columns." Journal of Composites for Construction, 16(6), 662-670.

$\mathrm{Xu}, \mathrm{Z}$., Hao, H., and Li, H. N. (2012). "Experimental study of dynamic compressive properties of fibre reinforced concrete material with different fibres." Materials \& Design, 33, 42-55. 